NBER WORKING PAPER SERIES

\title{
MARKET ACCESS, TRADE COSTS, AND TECHNOLOGY ADOPTION: EVIDENCE FROM NORTHERN TANZANIA
}

\author{
Shilpa Aggarwal \\ Brian Giera \\ Dahyeon Jeong \\ Jonathan Robinson \\ Alan Spearot \\ Working Paper 25253 \\ http://www.nber.org/papers/w25253
}

\author{
NATIONAL BUREAU OF ECONOMIC RESEARCH \\ 1050 Massachusetts Avenue \\ Cambridge, MA 02138 \\ November 2018
}

We are grateful to Sheah Deilami-Nugent and David Roughgarden for outstanding work coordinating field activities, and BRAC Tanzania and IPA Tanzania for administrative support. We thank Patrick Olobo for his collaboration. Anouk Faoure, Petra Gram, Matthew Krupoff and Alexandra Murphy provided excellent research assistance. We thank Lauren Falcao Bergquist, Shoumitro Chaterjee, Alain de Janvry, Betty Sadoulet and seminar participants at Ashoka University, Cal Poly San Luis Obispo, UC Berkeley, ISB, LSE, the University of Maryland, NBER Trade and Agriculture Conference, NEUDC, the University of Virginia, UCSC, the University of West Virginia and, the WEAI, the University of Pittsburgh, and Stanford University for helpful comments. We acknowledge funding from the IGC (grant 1-VRC-VTZAVXXXX-89307), the National Science Foundation (SES 1658942), Innovations for Poverty Action, ISB and UCSC. The data collection approval was approved by the IRBs of UCSC and the Indian School of Business, and by the Tanzania Commission for Science and Technology (COSTECH). The views expressed herein are those of the authors and do not necessarily reflect the views of the National Bureau of Economic Research.

NBER working papers are circulated for discussion and comment purposes. They have not been peer-reviewed or been subject to the review by the NBER Board of Directors that accompanies official NBER publications.

(C) 2018 by Shilpa Aggarwal, Brian Giera, Dahyeon Jeong, Jonathan Robinson, and Alan Spearot. All rights reserved. Short sections of text, not to exceed two paragraphs, may be quoted without explicit permission provided that full credit, including $\odot$ notice, is given to the source. 
Market Access, Trade Costs, and Technology Adoption: Evidence from Northern Tanzania Shilpa Aggarwal, Brian Giera, Dahyeon Jeong, Jonathan Robinson, and Alan Spearot NBER Working Paper No. 25253

November 2018

JEL No. F14,O12,O13,O18,Q12

\begin{abstract}
$\underline{\text { ABSTRACT }}$
In this paper, we quantify market access in rural Tanzania, and the extent to which it constrains agricultural productivity. We collect granular data on farmer input and sales decisions, input and output prices, and travel costs in all 1,183 villages in two regions of Tanzania. We find that a village in the 90th percentile of the travel-cost adjusted price distribution faces input and output prices $40-55 \%$ less favorable than a village at the 10th percentile. In reduced form, an additional standard deviation of travel time is associated with 20-25\% lower input adoption and output sales. We develop and quantify a spatial model of input adoption and conservatively estimate that farmers behave as if they face travel costs of $6 \%$ ad-valorem per kilometer of travel, which is equivalent to $40 \%$ when traveling to the closest retailer. Holding exogenous local factors fixed, we estimate that reducing travel costs by $50 \%$ (approximately the effect of paving rural roads) doubles adoption and reduces the adoption-remoteness gradient by $18 \%$.
\end{abstract}

Shilpa Aggarwal

Indian School of Business

Gachibowli, Hyderabad 500032

India

shilpa_aggarwal@isb.edu

Brian Giera

Amazon Research

69 Alta Vista Dr.

Santa Cruz, CA, 95060

bgiera14@gmail.com

Dahyeon Jeong

University of California, Santa Cruz

dajeong@ucsc.edu
Jonathan Robinson

Department of Economics

University of California, Santa Cruz

457 Engineering 2

Santa Cruz, CA 95064

and NBER

jmrtwo@ucsc.edu

Alan Spearot

University of California, Santa Cruz

acspearot@gmail.com 


\section{Introduction}

It is widely believed that poor access to markets - due mainly to poor transportation infrastructure - limits agricultural productivity in rural areas of developing countries, by making it harder to access productivity-enhancing inputs like fertilizer and to obtain high prices for harvest output (World Bank, 2008; 2017) 1] However, while remoteness no doubt limits market access, there is little research to rigorously quantify its effect.

In this paper, we rigorously document market access among farmers in two regions - Kilimanjaro and Manyara - of Northern Tanzania. Together, these two regions represent 6 percent of the land area and population of the country. Our data collection exercise spans the entire supply chain of maize (output) as well as of fertilizer (input) in all 1,183 villages in these two regions, including (1) surveys with a random sample of 2,845 farmers in 246 randomly selected villages; (2) surveys with 532 agro-input retailers (agrovets) that sell fertilizer (this sample represents the universe of retail locations available to farmers) $:^{2}(3)$ a retrospective panel of monthly buying and selling prices of maize from a randomly selected sample of maize-sellers in each of the 226 markets in the area; (4) collection of information on road quality, travel times, and travel costs to all villages from their respective local markets as well as from 6 major urban centers, and travel times and costs between each market and each major urban center; and (5) driving times and distances pulled from Google Maps API for the universe of bilateral village pairs, as well as for pairs of villages and major urban centers across central and northern Tanzania, plus Dar es Salaam.

We make three main contributions. First, we precisely document spatial price dispersion for input and output prices, inclusive of trade costs. To do this, we use our extensive travel cost data to estimate travel costs to every destination, and then take the most favorable prices for farmers. We find clear evidence of large and economically meaningful spatial heterogeneity in both input and output prices. For both, we find that the price difference between the 90th and the 10th percentile of delivered input prices is equivalent to about $50 \%$ of the mean. We find similar evidence of greatly reduced market access in remote rural areas using a variety of other measures.

Second, we conduct a reduced-form investigation of the correlation between usage and remoteness on the input side, and sales and remoteness on the output side, where remoteness of any location is proxied by the weighted average of travel times from a set of local regional hubs. We find striking correlations between remoteness and all measures of input usage and output sales. In particular, we find that a standard deviation increase in remoteness is associated with a 9-17 percentage point reduction in the probability of using fertilizer and a 6-9 percentage point reduction in the probability of selling maize. Put differently, we find that input usage in the most remote villages in our study sample is approximately only a third of that in the least remote villages, while

\footnotetext{
${ }^{1}$ Transportation infrastructure is particularly underdeveloped in Africa as the continent has only 137 kilometers of roads per 1000 square kilometers of land area, with only a quarter paved. In contrast, the average for developing countries outside the region is 211 kilometers of roads per 1000 square kilometers, with more than half paved (World Bank, 2010). For comparison, the US has 679 kilometers per 1000 square kilometers, with nearly 2/3 paved.

${ }^{2}$ As discussed later, we successfully surveyed 532 agrovet out of a universe of 585 . For the remaining agrovets, we impute prices as described later.
} 
maize sales are only 45 percent as high.

While we find clear evidence of reduced market access, and while it is also clear that this reduced access will affect the choice set and decisions of farmers, it is not possible to quantify these effects in the reduced form alone, since remote villages and villagers may differ in other ways as well. To perform this quantification absent experimental variation, our third contribution is to develop a spatial model of fertilizer adoption in which the decision to adopt fertilizer is based on local output prices, innate farmer productivity, the distribution of delivered input prices and retailer quality, and idiosyncratic shocks. Transportation costs affect the distribution of prices by increasing the costs for farmers to reach a particular agrovet to buy inputs, as well as those to reach the local market to sell their harvest.

On the input side, the structure of the model (which is based on Eaton and Kortum, 2002) facilitates a decomposition of choosing an agrovet into three components, (1) the decision whether to adopt anywhere; (2), the decision of which location to buy from; and (3) the decision of which retailer to pick within that location. Our novel farmer surveys reliably record the first two of these decisions, and also allow us to calibrate (1) local non-price factors that may affect adoption, and (2) the implied trade cost of choosing an agrovet. On the latter, we derive a novel multinomial logit specification that estimates the implied iceberg trade costs to each location as a function of distance, while using location-specific dummies to account for other amenities available at each location (which may represent unmodeled issues like experience in selling inputs and likelihood of stockouts). The results suggest that transportation costs are large: our preferred specification yields estimates of local iceberg cost that are, at the conservative end, $6 \%$ ad-valorem per kilometer of travel. This is approximately $40 \%$ to reach the average closest agrovet, and thus these costs are economically meaningful, and suggest significant non-pecuniary costs of travel. These may include other factors such as the opportunity cost of the time to travel, risk-aversion related to potential stockouts, or information frictions, among others. After estimating trade costs, we use the model to build a market-clearing condition for fertilizer for each agrovet, which is a function of the spatial distribution of fertilizer expenditures by each farmer and the probability that a farmer at each location adopts at a given agrovet. We balance these market clearing conditions by finding a vector of agrovet "amenities" that exactly rationalize the market-shares of each agrovet.

Finally, we use the estimated parameters from the model to simulate market access counterfactuals. For input market access, our primary counterfactual is reducing trade costs incurred to reach retailers by $50 \%$, which is roughly equivalent to the realized reduction in travel time due to road upgrading (Casaburi, Glennerster and Suri 2013). This policy roughly doubles adoption relative to baseline, and also reduces the distance gradient by $18 \%$. We also evaluate how the costs for retailers to source inputs from distributors affect the adoption decision. After cutting the wholesaler-retailer transportation costs by half, adoption rises by about 1 percentage point, or $4 \%$, and yields a $4 \%$ reduction in the remoteness-adoption gradient. We also study hypothetical entry counterfactuals, where we find that while agrovet entry in remote areas has a larger effect on adoption, the profitability from doing so falls by 0.35 log points for each standard deviation 
increase in remoteness. Finally, subject to a number of caveats based on data availability for maize markets, we reduce transportation costs by $50 \%$ for reaching output markets, and find a slightly smaller change in adoption, though a slightly larger reduction in the adoption-remoteness gradient (when compared with input market access).

This paper sits at the intersection of trade and development economics. On the development side, our paper contributes to a literature examining why Sub-Saharan Africa has lagged behind the rest of the developing world in agricultural technology adoption (World Bank 2008). Many studies find evidence of large yield increases of using improved inputs (i.e. Duflo, Kremer and Robinson 2008; Beaman et al. 2013; Stewart et al. 2005; Udry and Anagol 2006), though the evidence is much more mixed on whether using these inputs is profitable (i.e. Duflo, Kremer and Robinson 2008; Beaman et al. 2013). Our results quantify the extent to which profitability, and thus adoption, will tend to be lower in more remote locations, due to less favorable input and output prices for farmers. In this sense, our work is closely related to Suri (2011), who shows that many Kenyan farmers with high gross returns to hybrid seeds choose not to adopt them because the fixed costs of obtaining seeds are too high, presumably due to travel costs. Our paper is differentiated by focusing on heterogeneity in market access, rather than on heterogeneity in returns. Related work in Minten, Koru, and Stifel (2013) also focuses on remoteness and profitability and documents significant farmer-to-retailer transaction costs to reach price-controlled input cooperatives in a rugged region in northern Ethiopia $3^{3}$

Our paper is related to a rapidly growing literature about the effect of roads or other infrastructure improvements on development outcomes and on the spatial distribution of economic activity 4 which includes a whole host of outcomes other than just prices, including consumption diversity, farm investments, human capital investment, migration, and occupation choice (Aggarwal, 2018a; b; Adukia et al., 2016; Asher and Novosad 2016; Brooks and Donovan, 2017; Morten and Oliveira 2016). In our paper, we focus narrowly on the specific effect of transportation costs on market access (i.e. the actual time and money costs of transportation and the presence of intermediaries and the prices they charge) in isolation, without changing other margins. 5

Our work is also related to a voluminous trade literature which attributes price differentials across space to three primary components - marginal trade costs (e.g. Donaldson, 2018; Eaton and Kortum, 2002; Keller and Shiue, 2007; Sotelo, 2018), spatially varying mark-ups (Atkin and Donaldson, 2015; Asturias et al., 2017), and the organization of intermediaries (Allen and Atkin,

\footnotetext{
${ }^{3}$ Specifically, the authors document the farmer-reported cost of renting cargo transport (predominantly a donkey in this region) and the time cost of travel for a trip to the market town along the only route of egress from their villages. Our study differs in its focus on access to all, privately owned intermediaries for inputs, the costs of transport along both rural and feeder roads, and also the quantification of the adoption decision through the lens of a spatial economic model.

${ }^{4}$ A partial listing of papers includes Aggarwal (2018), Alder (2017), Adukia et al. (2016), Asher and Novosad (2016), Banerjee et al. (2012), Bird and Straub (2016), Bryan and Morten (2017), Gertler et al. (2014), Ghani et al. (2016), Khanna (2016), Shamdasani (2016), and Storeygard (2016). See Donaldson (2016) for a review.

${ }^{5}$ Technological advances may make it possible to decouple market access from traditional road infrastructure. For example, Rwanda has a "droneport" already under construction just outside the city of Kibuye, and which will be ready by 2020. Drones capable of transporting cargo of up to 20 kilos over a distance of 100 kms already exist.
} 
2016; Dhingra and Tenreyro, 2017; Bergquist, 2017; Casaburi and Reed, 2017; Chatterjee, 2018). Our paper is most closely related to Atkin and Donaldson (2015), who estimate trade costs in a situation in which an oligopolist intermediary buys products at wholesale prices, transports them to distant markets and sells them directly to consumers. By contrast, we are interested in how trade costs affect the buying decisions of final consumers (in this case, farmers), as well as pricing decisions by retailers. 6

Finally, much of the trade literature, which has documented larger gains from integration when there are input-output relationships (e.g. Yi, 2001; Costinot and Rodriguez-Clare, 2014; Sotelo, 2016) has only evaluated economies under the assumption of monopolistically competitive or purely competitive sectors at a fairly aggregate level (e.g. international trade by industry) [7 By contrast, our model yields a structural discrete choice problem in which farmers choose whether to adopt, and if so, choose the best agrovet from which to purchase fertilizer from a potentially concentrated group of agro-retailers. 8

The rest of this paper proceeds as follows. Section 2 provides background and context on our study region, and lays out the sampling strategy that was adopted for this project. Section 3 explains the data, and documents summary statistics about the various data-collection units. Section 4 presents our main results. We put our findings in the context of a spatial model, which is presented and calibrated in Section 5, and run policy counterfactuals in Section 6. Section 7 discusses the validity of our results outside of the study context of Northern Tanzania. Section 8 concludes with a discussion.

\section{Background on fertilizer market and study regions}

This study took place in the Kilimanjaro and Manyara regions 9 of Northern Tanzania. The two regions are a combined 57,000 square-kilometers (6\% of the land mass of Tanzania), contain 1,183 villages, and had a population of 3.1 million in 2012 (National Bureau of Statistics, 2013). Compared to developed countries, the quality of roads in Kilimanjaro and Manyara is very poor: for example, the paved trunk road density is 2.2 percent in Kilimanjaro (i.e. there are 2.2 kilometers of paved

\footnotetext{
${ }^{6}$ Though not directly comparable since they are at different points in the supply chain, our average ad-valorem "travel costs" of farmers procuring fertilizer, as calculated through interviews with transport providers, turn out to be similar to those of the intermediaries in Atkin and Donaldson (2015). Our costs, however, are calculated over a much shorter trip. Specifically, to find the best travel-adjusted price for fertilizer, our results suggest that for the typical village, the best option is $10 \mathrm{~km}$ away. In Atkin and Donaldson, ad-valorem estimates are calculated based on the cost difference of a trip to the most remote location (500 miles away) relative to the least remote location (50 miles away), which is approximately a $720 \mathrm{~km}$ difference.

${ }^{7}$ Our work is closely related to Sotelo (2016) develops a model of regional trade in agriculture and road quality in Peru to study the impact of road and output shocks on regional welfare and crop choice. Our work differs in its focus on local intermediaries and how their presence affects the landscape of market access.

${ }^{8} \mathrm{Yi}(2001)$ provides an influential take on the role of vertical relationships in the growth of vertical trade that is germane to our work. Intuitively, if inputs are traded from one country to another, and then final goods are traded back to the origin country, the role of distance is amplified by the multiple stages of production. That is, since borders must be crossed more than once, the costs of distance are amplified by the number of times the good crosses the border prior to consumption. Our field work has identified that economy in rural Tanzania is similar to this setting, where inputs are sourced from larger cities, and output, if sold at all, is trade back to these same cities.

${ }^{9}$ Tanzania has 31 regions in all, including 5 in Zanzibar.
} 
roads per 100 square kilometers of area), 0.15 percent in Manyara, and 0.7 percent in Tanzania overall (TanRoads and PMO-RALG, 2014), compared to 68 percent in the US and an OECD average of 134 percent 10

The main crop grown in this area is maize. There are two growing seasons in this area: a longer, more productive "long rains" season, which runs from March to June, and a less productive "short rains" season from October to January. Input usage tends to be much higher in the long rains, and some farmers decide not to plant in the short rains at all. Our main outcomes are based on behavior in the long rains.

As in much of Sub-Saharan Africa, production capacity of fertilizer is virtually non-existent in Tanzania and almost all of what is used is imported via the port at Dar es Salaam (FAOSTAT Online database, 2016; Hernandez and Torero, 2011), and then transported throughout the country over surface roads, including to the study regions. In all of these respects, the study area is fairly similar to other countries throughout East Africa that predominantly grow maize and import fertilizer, such as Kenya, and perhaps a little bit better than landlocked countries such as Malawi and Uganda, that can receive fertilizer only after it has traversed the distance between a neighboring coastal nation's port and their shared border, and then must travel further inland to reach farmers.

\section{Data and summary statistics}

To construct our sample, we first assigned every village in our sample to a market catchment area. This was done by visiting ward offices (the ward is the lowest administrative level in Tanzania) and asking the ward officer to list the market that people from that village frequented. We use this market designation as the unit over which to measure the price of maize, which is commonly transacted in such markets, We use this market information in two main ways. First, we randomly selected markets for inclusion in the price collection from this list. Second, it was not feasible to travel individually from every village to a particular point to measure transport costs. Instead, we measure transport costs, requiring routes to go through the market center - we measure distances from every village to its closest market, and from every market to the main road. A map of the villages in our sample is included as Figures 1.

We have four main sources of data we use in this draft: agrovet surveys, farmer surveys, transport surveys, and maize price surveys. All were collected from January 2016 to December 2017 in Kilimanjaro and February to May 2018 in Manyara.11

\footnotetext{
${ }^{10}$ Information compiled from various resources. The Roads Act, 2007 (No. 13 of 2007) defines a a trunk road as one that is primarily (i) a national route that links two or more regional headquarters or (ii) an international through route that links regional headquarters and another major or important city or town or major port outside Tanzania. A regional road is a secondary national road that connects (i) a trunk and district or regional headquarters; (ii) a regional headquarters and district headquarters.

${ }^{11}$ We also collected data on maize intermediaries who buy directly from farmers ("agents") and on larger warehouses that buy from these agents ("stores"), as well as logbooks of transactions from stores. We do not utilize this data in this version of the paper.
} 


\subsection{Agrovet surveys}

We conducted a census of all agricultural input retailers (known as "agrovets" locally) in the region, finding a total of 585 that sold either fertilizer or seeds. agrovets. We then revisited these agrovets to conduct a longer survey which took about 2 hours to complete. Of these 585, we did surveys with 532 of them (see Web Appendix Table A1, which reports survey compliance and attrition). The survey asked questions about varieties of fertilizer sold, and their prices, quantities, and the wholesale costs of acquiring stock from the distributor. The survey took care to differentiate fertilizer types by distributor, brand, and type - thus the level of granularity should be akin to the barcode-level. The survey also included a number of questions about costs of travel to the distributor, as well as some background characteristics.

\subsection{Farmer surveys}

We conducted farmer surveys in 246 randomly selected villages in three waves. The first wave occurred in 115 villages in Kilimanjaro in early 2016, the second wave in 97 villages in Kilimanjaro in 2017, and the third wave in 50 villages in Manyara in 2018. The surveys included questions on input usage and prices, transport costs and agrovet choice, maize sales, harvest output, and a series of household and demographic questions. Though the exact questions varied from survey to survey, the general format was very similar across rounds. The main difference across rounds was the sampling procedure and the number of farmers enrolled per village: in round 1, households were selected from a random walk procedure ${ }^{12}$, while in rounds 2-3 households were pre-identified from a village listing exercise conducted with local leaders. In Wave 1 , we sampled only 5 households per village for budget reasons, while in Waves 2-3 we selected 18 households per village. While this differing sampling procedure could result in differential selection, we find no qualitative difference in results from the two methods, and thus we pool all surveys together in the analysis.13

\subsection{Measuring transport costs}

One of the primary contributions of this work is to carefully document transport costs incurred by farmers. We measured transportation costs in several ways. First, we collected GPS location for every village in both the study regions ${ }^{14}$ from which we calculated driving times and distances using the Google API (via the statistical program R). Second, we conducted surveys of transportation operators in every village in our sample, which were either motorbike taxis ("Boda Bodas"), or consumer van taxis ("Dala Dalas"). In each village, we asked up to 3 operators how much it cost to

\footnotetext{
${ }^{12}$ In particular, enumerators were instructed to first find a landmark. These landmarks included a primary/secondary school within the village (1st choice), local church within the village (2nd), Boda stand within the village (3rd). Once the landmark was identified, the enumerators randomly picked a direction to begin their fieldwork, and selected every third homestead, or the next homestead after five minutes of walking, whichever came first.

${ }^{13}$ Results disaggregated by survey method are available on request.

${ }^{14}$ We cross-checked these GPS coordinates, and filled in a handful of missing values, using a dataset of postal geocodes from www.geopostcodes.com.
} 
travel to the major towns in Kilimanjaro (Arusha and Moshi), the capital city (Dar es Salaam) and the market center. In Manyara, in addition to Arusha, Moshi and Dar es Salaam, we also asked about trip costs and times to Babati, Dodoma, and Tanga.

Third, enumerators recorded information on road quality and travel times as part of their field work. To get to a market center and village from a major hub, enumerators took the standard routes, which usually entailed travel for some distance along a major trunk road, and then turning off to travel for some time on unpaved feeder roads and village roads. To measure travel times, field officers recorded their GPS location at the point at which they had to turn off the main road, and then recorded the travel time, distance, and road quality on the road to the market center associated with the village. Once reaching the market, enumerators took a second form of transportation to the village, recording again distance, travel time, and road quality. We use this data to correlate costs of travel with road quality, and to estimate the percentage of roads which are paved versus gravel or dirt (to inform later counterfactuals).

\subsection{Maize prices}

To measure maize prices, we visited markets post-harvest in September and October of 2017 in Kilimanjaro and February to May of 2018 in Manyara. During these visits, enumerators sampled up to 3 maize sellers per market to document pre- and post-harvest prices for maize during recent seasons. These data allow us to compare prices across markets at the same point in time, though they are not intended to be used in panel analysis.

\subsection{Summary statistics on villages}

A map of Kilimanjaro and Manyara is shown in Figure 1. We surveyed all villages in these regions. Summary statistics on villages are provided in Table 1 . The average village has 2,842 people (see table notes), and is located 11.3 kilometers from the nearest market center. It takes about 40 minutes by vehicle to reach the market and a round-trip costs about $\$ 1.92$ on average. The average village is over $70 \mathrm{~km}$ away from a major hub, and travel there would be an almost 3 hours-long round-trip, and cost $\$ 6$. For both measures, there are many villages that are much further away than this - the standard deviation of both is large.

Panel B shows information on the quality of the rural roads connecting markets and villages. Roads are about $1 / 3$ paved, $1 / 3$ dirt, and $1 / 3$ gravel, and travel times according to google are fairly slow: $30.6 \mathrm{~km} /$ hour on rural roads compared to $49.5 \mathrm{~km} /$ hour on the main roads.

\section{Results}

\subsection{Defining remoteness}

We define remoteness as proximity to major hub towns, where distributors are located. There are a number of potential hubs, but they differ in their importance. To capture this, we weight 
the distance to each town by the population of that town - the rationale for this is that bigger population centers will have more distributors than smaller ones. Our measure of remoteness for each village $v$ therefore becomes

$$
\text { remoteness } v=\sum_{h} \frac{d_{h v}}{\operatorname{pop}_{h}}
$$

where $\operatorname{pop}_{h}$ is the population of hub $h$ and $d_{h v}$ is distance from village $v$ to that hub. For interpretation, we standardize this measure to have mean 0 and standard deviation 1 . The distribution of this variable can be seen in Web Appendix Figure A1. The least remote areas (near major hubs) are approximately -2 standard deviations from the mean, while the most remote are +3 standard deviations away. The difference between these ( 5 standard deviations) is useful for benchmarking differences in outcomes between the most and least remote areas (similar to the approach taken in Atkin and Donaldson, 2015)

\subsection{Calculating travel cost-adjusted prices}

For each village, we assume that farmers are free to travel to any market to buy or sell, but must incur a transportation cost, which we calibrate using information from transport surveys and google distances. Specifically, using Google API, we calculate the route from every village to every agrovet. This route will involve either (1) traveling only on local roads over a relatively short distance, or (2) using local roads to connect to trunk roads. We calibrate the costs of local and trunk roads using our transport operator surveys, and information collected by enumerators during their own travel. We present these results in Table 2. Columns 1-3 show costs of traveling from market centers to hub towns, which involves primarily traveling on trunk roads. We find a cost of about $\$ 0.021$ per $\mathrm{km}$, or $\$ 1.20$ per hour of travel. The remaining columns replicate this on rural roads, where we find higher costs for rural travel.

With these, we calculate a travel cost-adjusted price of fertilizer for every village as follows:

$$
r_{v}^{t c}=\min _{j}\left\{r_{j}+c_{j v}\right\}
$$

where $r_{j}$ is the price at agrovet $j$ and $c_{j v}$ is the cost of traveling to an agrovet, and returning with a bag of fertilizer from agrovet $j$ to village $v$. Farmers must therefore make a round-trip for themselves, and a one-way trip for the fertilizer itself. To calibrate these costs, we use survey questions which asked those farmers who traveled to market about travel costs for themselves and the fertilizer (Web Appendix Table A1). We do this for a $50 \mathrm{~kg}$ bag of fertilizer, the modal amount purchased by farmers. We find that transporting a $50 \mathrm{~kg}$ bag of fertilizer costs about $75 \%$ as much as transporting a person over the same distance, implying therefore that a farmer must make 2.75 trips to buy a bag ( 2 for himself and 0.75 for the bag).

For maize prices, we adopt a similar approach, but instead construct the maximum travel costadjusted selling price for maize: 


$$
p_{v}^{t c}=\max _{m}\left\{p_{m}-c_{m v}\right\}
$$

Here, $p_{m}$ is the price of maize post-harvest for market $m$, and $c_{m v}$ is the cost of traveling from village $v$ to market $m$. We use a $120 \mathrm{~kg}$ bag for this calculation, and assume that the cost of transport is twice that of fertilizer (i.e. proportional to the size).

We calculate these prices for every village-agrovet and village-market pair. We then take the minimum input price and the maximum output price faced by each village. Our first main result is that we find substantial heterogeneity in these measures of travel cost-adjusted prices. Figure 2 plots CDFs of village-level "best" prices of inputs and output, adjusting for travel costs, and show tremendous heterogeneity in prices across villages. In Panel A, for maize prices, we observe that one standard deviation in the best travel cost-adjusted selling price of maize is $15 \%$ of the mean, and the ratio of this price between the 90th and the 10th percentile ratio is similar to about $40 \%$ of the mean. Panel B shows the distribution of transportation cost-adjusted fertilizer prices, where the standard deviation in travel cost-adjusted prices is $15 \%$ of the mean, and ratio of this price between the 90 th and the 10 th percentile is equivalent to about $60 \%$ of the mean.

\subsection{Reduced form analysis}

\subsubsection{Specification}

From the above data sources, we are able to construct transportation costs to every village in our sample, using either survey transport costs or Google maps. Our main empirical specification then becomes:

$$
m_{v t}=\text { Aremoteness }_{v}+\epsilon_{v t}
$$

where $m_{v t}$ is a measure of market access (or related outcome) at location $v$ in year $t$.

TFor the market access measures estimated as above, we include no controls. However, for farmer outcomes such as input adoption, it is clear that usage will depend not only on market access but also other characteristics such as income and land suitability. Therefore, these are estimated at the farmer level as:

$$
m_{f v t}=\text { rremoteness }_{v}+\beta X_{f v t}+\epsilon_{f v t}
$$

where subscript $f$ refers to farmer and $\mathbf{X}_{\mathbf{f v t}}$ is a vector of other controls. These controls include a host of characteristics from the survey, such as land ownership, income, asset ownership, education and other demographic characteristics, as well as soil information from the FAO-GAEZ. All farmerlevel results are presented both with and without these controls.

\subsubsection{Summary statistics and correlations with remoteness}

Table 3 shows some statistics on demographic and background characteristics, buying and selling of maize, production capacity and harvest output, and displays how these variables vary with 
remoteness. From Panel A, we see a number of differences: farmers in more rural areas are less educated, own fewer assets, have less access to finance, and earn less income from sources outside of farming. These farmers also tend to have larger families and larger farms. These differences must be accounted for when doing policy counterfactuals.

Panel B shows production capacity, based on GIS data from the FAO-GAEZ database, which provides information on counterfactual yields with and without inputs. The key concern here would be that more remote areas are less suitable for fertilizer, for whatever reason. At the mean, the FAO estimates that using inputs would more than quadruple yields. We do find that the yield increase is lower in rural areas - in villages one standard deviation away from the mean, yields

using inputs are $260 \%$ of those without inputs, compared to over $300 \%$ at the mean. Comparing the most and least remote areas (roughly from -2 to 3 standard deviations), we estimate a yield increase of over $500 \%$ in the least remote areas compared to $200 \%$ in the most remote. Thus, while we should expect lower usage in remote areas since returns are lower, the yield increases are still extremely large everywhere. We control for these measures in our main regressions.

Finally, Panel $\mathrm{C}$ shows harvest output from the most recent long rains. Total yields are similar by remoteness, but yield per acre is lower in rural areas (since farm size is larger). In particular, 1 standard deviation increase in remoteness is associated with a reduction in harvest output per acre of about $20 \%$. This is consistent with lower input usage in rural areas, or with differences in other factors such as soil quality.

In conclusion, Table 3 makes clear that it is difficult to pinpoint the role of input prices on outcomes, since access to roads is correlated with so many characteristics. Ultimately this motivates the use of an economic model to conduct counterfactuals.

\subsubsection{Access to input markets}

Table 4 shows how remoteness correlates with access to input markets. We first tabulate access to retailers over a distance that is reasonably traveled by farmers. Web Appendix Figure A2 shows a CDF of the distance farmers travel to access inputs, conditional on purchase. We find that approximately $60 \%$ of purchases are made within $10 \mathrm{~km}$ of a farmer's village, and $80 \%$ within 20 $\mathrm{km}$. We therefore show results within $10 \mathrm{~km}$ of a farmer's village. Panel A shows several measures of retailer activity in the area, including a dummy for whether there is at least one retailer within $10 \mathrm{~km}$, the number of retailers within $10 \mathrm{~km}$, and the minimum distance to a retailer. On each measure, we find clear evidence of reduced access in remote villages, all significant at $1 \%$.

Panel B of Table 4 shows our key measure of access, travel cost-adjusted prices. We find that one standard deviation of remoteness raises prices by about $\$ 2.3$, equivalent to about $9.5 \%$ of the mean. This implies a difference in prices of approximately $50 \%$ between the most and least remote villages in our study sample. We then decompose this price difference into differences in the price itself, and in the travel cost. We find that the contributions of retail prices and transportation costs are approximately equal in their contribution toward the increase in delivered prices.

To investigate this further, we look at agrovet pricing in Web Appendix Table A3. We note 
that these results should be taken with some caution, since they are conditional on entry (i.e. the agrovet location is not exogenous), and so we take these as more descriptive than definitive. Panel A shows the gradient of distance on sales and product variety, showing little heterogeneity except for the costs of reaching a wholesaler. In surveys, we find that nearly all agrovets travel themselves to distributors to access inputs, and we find that these costs are higher in rural areas (naturally), since they must travel further.

Panel B shows the relationship on prices and markups. Note that these regressions are the fertilizer type level (i.e. product barcode). We find some weak evidence that rural shops face slightly higher wholesale prices (significant at only 10\%) and some stronger evidence that they charge higher retail prices. The effect is modest though statistically significant: a 1 standard deviation increase in distances is associated with $2.5 \%$ higher prices. We then calculate markups, inclusive of transport costs. We find no strong evidence of differential markups in rural areas - while retail prices are higher, this is largely due to transport costs directly passing through to farmers. From this, we conclude that much of the higher retail prices are a result of higher marginal costs of accessing inputs 15

\subsubsection{Access to output markets}

Table 5 performs a similar analysis, but on the output side. As before, Panel A shows that more remote villages are less likely to have a market within $10 \mathrm{~km}$ and have to travel farther to reach a market where maize is sold. Panel B shows travel cost-adjusted prices for maize. Since there are large seasonal price fluctuations in rural Tanzania as in much of rural Africa ${ }^{16}$ we use a price for the single point in time which is most relevant for farmers: immediately post-harvest. Our surveys show that most farmers who sell do so shortly after harvest. We find that travel cost-adjusted prices of output are lower in remote areas. As before, we decompose this into the retail price and the travel costs, finding that while retail maize prices rise modestly, transport costs to the closest maize market rise by $\$ 3.9$ with each standard deviation in remoteness, overwhelming the increase in price of maize.

Finally, we show 2 other measures of price, measured at the village level: (1) we asked farmers what the "going price" of maize was after the last harvest; (2) we collected information on sales

\footnotetext{
${ }^{15}$ In Web Appendix Table A4, we conduct two robustness checks. First, we only surveyed retailers within the regional boundaries and thus have no information on retailers in neighboring regions. While most of these boundary areas are remote, it is nevertheless possible that there exist lower-priced retailers just over regional boundaries. Since we miss these, we may overstate travel cost-adjusted prices. To address this, we drop all villages within $10 \mathrm{~km}$ of regional boundaries - results are actually stronger. Second, while we had high survey completion rates among agrovets (91\% - see Web Appendix Table A1), we nevertheless do not have the universe of retail options. This suggests that retail price heterogeneity is understated. However, it may affect the regression results. To address this, we conduct a bounding exercise in Web Appendix Table A4, Panel B. In this exercise, we estimate the distribution of prices within regions. We then assign prices in the tails of this distribution (the 10th or 90th percentile) to missing agrovets in a way that attenuate our regression results - for example, in remote areas, we assign agrovets low prices. This exercise lowers the coefficient marginally, but the qualitative results are unchanged.

${ }^{16}$ Aggarwal, Francis and Robinson (2018) document an average price increase of about $46 \%$ over the season for the years 2006-16 in Kisumu market in neighboring Kenya; Bergquist, Burke, and Miguel document increases in the range of $15-30 \%$ for a sample of markets in the east African region.
} 
prices for all farmers who sold maize. While this latter measure is affected by selection, we minimize this problem by taking the average sales prices across the village. Both of these show no correlation with distance.

\subsubsection{Farmer decisions}

The results so far show clear evidence of reduced market access on both input and output markets, and of higher prices for inputs and lower (travel cost-adjusted) prices for output. These results should imply lower input usage and maize sales in rural areas. We investigate this in Table 6, where we present results with and without a full set of farmer controls from the surveys (Columns 2-3). In Panel A, we present indicators for using inputs as well as the quantity used, for both seeds and fertilizer. In all specifications, these relationships are very strong (significant at 1\%) and large. We find that use of fertilizer is 9-17 percentage points lower in villages 1 standard deviation away, and that of hybrid seeds is 5-7 percentage points lower. Since the distance between the least and most remote regions is about 5 standard deviations, the regressions predict approximately a minimum of 45 percentage point lower usage in the most remote villages, which translates to about $80 \%$ of the mean in the least remote areas. The effect for seeds is smaller but still evident.

Similarly, in Panel B, we see strong evidence that sales are lower in remote areas. While the regression predicts that $44 \%$ of farmers will sell in the semi-urban areas, this declines to only $14 \%$ in the most remote areas. This is predominantly coming from a decline in sales to agents (since agents are by far the most common way to sell maize), but there are declines in sales at the market as well.

Consistent with this, Panel $\mathrm{C}$ shows buying behavior. Rural farmers are more likely to buy maize and are more likely to be net buyers of maize. Interestingly, we find a lot of heterogeneity in net buying behavior. We find that $37 \%$ of farmers buy maize but sell none, $24 \%$ sell maize but buy none, and only $8 \%$ buy and sell maize (the other $30 \%$ do not transact on either side of the market). The proportion that report buying and selling is lower than in other recent work such as Bergquist, Burke and Miguel (2018) ${ }^{17}$

\section{Model}

The reduced form results summarized above suggest that more remote farmers suffer from reduced access to input retailers as well as selling opportunities. However, as other factors are also correlated with distance, we now quantify the impact of access to input and output markets by developing a spatial model of fertilizer adoption. In the model, we will be careful to develop a rigorous model of retailer choice, including for reasons unrelated to trade costs, as well as allowing for other factors that may affect adoption but not related to input access.

\footnotetext{
${ }^{17}$ See Web Appendix Figures A3 and A4 for a scatter plot of several of the key outcomes.
} 


\subsection{Model Preliminaries}

\section{Production and Inputs}

We begin the model by presenting the two technologies available to farmers, and the role of retailer choice in (potentially) affecting farmer productivity. The production function without fertilizer is:

$$
Y_{i}=\widetilde{\theta}_{i 0} K_{i}^{\alpha_{0}} L_{i}^{1-\alpha_{0}}
$$

Here, $\widetilde{\theta}_{i 0}$ is baseline productivity without fertilizer for farmer $i, K_{i}$ is land held by farmer $i$, and $L_{i}$ is labor hired/used by farmer $i$. If the going wage rate in $i$ is $w_{i}$ and the selling price of maize is $p_{i}$, holding land fixed, profits can be derived as:

$$
\begin{aligned}
\Pi_{i 0} & =\alpha_{0}\left(1-\alpha_{0}\right)^{\frac{1-\alpha_{0}}{\alpha_{0}} \widetilde{\theta}_{i 0}^{\frac{1-\alpha_{0}}{\alpha_{0}}}} p_{i}^{\frac{1}{\alpha_{0}}} w_{i}^{-\frac{1-\alpha_{0}}{\alpha_{0}}} K_{i} \\
& =\theta_{i 0} \pi_{i 0}
\end{aligned}
$$

Here, $\theta_{i 0}=\alpha_{0}\left(1-\alpha_{0}\right)^{\frac{1-\alpha_{0}}{\alpha_{0}}} \widetilde{\theta}_{i 0}^{\frac{1-\alpha_{0}}{\alpha_{0}}}$ and $\pi_{i 0}=p_{i}^{\frac{1}{\alpha_{0}}} w_{i}^{-\frac{1-\alpha_{0}}{\alpha_{0}}} K_{i}$. The former term, $\theta_{i 0}$, will be represented by a random variable with a village-specific mean, and the latter will be calculated as a function of observed data for farmer $i$ and elasticities that must be estimated.

The production function with fertilizer splits up variable inputs into labor and fertilizer, and also provides a productivity shock, $\widetilde{\theta}_{i j v}$ :

$$
Y_{i}=\widetilde{\theta}_{i j v} K^{\alpha} L^{(1-\alpha) \beta} M^{(1-\alpha)(1-\beta)}
$$

Note that we are assuming that the exponents on capital and labor may be different for the technology with fertilizer, and that farmer $i$ will receive a productivity of fertilizer that potentially varies by agrovet $j$ in location $v$. We discuss the motivation for this assumption shortly. Writing the delivered price of fertilizer to $i$ from agrovet $j$ in $v$ as $r_{i j v}$, solving for the optimal labor and fertilizer inputs, profits from adoption can be written as:

$$
\Pi_{i}=\theta_{i j v} \pi_{i} r_{i j v}^{-\sigma}
$$

where $\sigma \equiv \frac{1-\alpha}{\alpha}(1-\beta), \pi_{i}=p_{i}^{\frac{1}{\alpha_{0}}} w_{i}^{-\beta \frac{1-\alpha_{0}}{\alpha_{0}}} K_{i}$, and $\theta_{i j v}=\kappa_{2} \widetilde{\theta}_{i j v}^{\kappa_{1}}$ Here, the profitability of fertilizer is a function of the productivity shock, $\theta_{i j v}$, which we will assume is random and with a central moment that is dependent on the source of the fertilizer, the (delivered) price of fertilizer itself, $r_{i j v}$, and deterministic profits based on local observables and technology $\pi_{i}$.

\footnotetext{
${ }^{18} \kappa_{1}$ and $\kappa_{2}$ are constant functions of model parameters
} 


\section{Input and Agrovet Choice}

Farmers have a choice of whether to purchase fertilizer, and if so, where to purchase fertilizer, which itself is affected by prices for fertilizer at each agrovet location as well as the travel costs to get there and back. Suppose that the set of villages that contain an agrovet is defined as $\mathcal{V}$, where the price charged at location $v \in \mathcal{V}$ by agrovet $j$ is $r_{j v}$. The per-unit cost to the farmer $i$, inclusive of transport costs, will be written as $r_{i j v}=r_{j v} \tau_{i v}$, where $\tau_{i v}$ is an iceberg trade cost for farmer $i$ in traveling to $v$ and back. Further, we assume that $\theta_{i j v}$, is a random variable that could represent unobserved inputs purchased at agrovet $j$ or location $v$, or perhaps other networking and information that is acquired at location $v$ that may increase profitability. Whatever the interpretation, we assume that $\theta_{i j v}$ is distributed according to Fréchet distribution with location parameter $T_{j v}$ and dispersion parameter $\varepsilon$. Precisely:

$$
\operatorname{Pr}\left(\theta_{i j v}<\theta\right)=\exp \left(-T_{j v} \theta^{-\varepsilon}\right)
$$

Using this distributional assumption, the unconditional distribution of profits for farmer $i$ buying from agrovet $j$ in location $v$ is written as:

$$
\operatorname{Pr}\left(\Pi_{i j v}<\pi\right)=\exp \left(-T_{j v} \pi_{i}^{\varepsilon} r_{i j v}^{-\varepsilon \sigma} \pi^{-\varepsilon}\right)
$$

We also assume that the outside option of not buying fertilizer is random. Specifically, $\theta_{i 0}$ is distributed Fréchet with location parameter $T_{i 0}$. Thus, the distribution of profits is written as:

$$
\operatorname{Pr}\left(\Pi_{i 0}<\pi\right)=\exp \left(-T_{i 0} \pi_{i 0}^{\varepsilon} \pi^{-\varepsilon}\right)
$$

Here, we allow for the average productivity of the outside option of not buying fertilizer to vary by village $i$ through the location parameter $T_{i 0}$. This may reflect difficulties in using or adopting fertilizer that are specific to a location (poor soil quality, lack of training, existing norms, etc...).

Farmer $i$ chooses among locations $v \in \mathcal{V}$ and agrovets $j \in \mathcal{J}_{v}$ at each location to find the most profitable option. Solving the standard discrete choice problem (which is derived in the technical appendix), the probability that farmer $i$ buys from agrovet $j$ at location $v$ is written as:

$$
\lambda_{i j v}=\frac{T_{j v} \pi_{i}^{\varepsilon} r_{i j v}^{-\varepsilon \sigma}}{T_{i 0} \pi_{i 0}^{\varepsilon}+\sum_{v^{\prime} \in \mathcal{V}} \sum_{l \in \mathcal{J}_{v^{\prime}}} T_{l v^{\prime}} \pi_{i}^{\varepsilon} r_{i l v^{\prime}}^{-\varepsilon \sigma}}
$$

\section{Decomposing Choice Probabilities}

Note that (13) can be broken up into the probability of adoption for $i$, and the probability $i$ buys 
from $j$ at location $v$ conditional on buying:

$$
\begin{aligned}
\lambda_{i j v} & =\underbrace{\frac{\sum_{v^{\prime} \in \mathcal{V}} \sum_{l \in \mathcal{J}_{v^{\prime}}} T_{l v^{\prime}} r_{i l v^{\prime}}^{-\varepsilon \sigma}}{T_{i 0}\left(\frac{\pi_{i 0}}{\pi_{i}}\right)^{\varepsilon}+\sum_{v^{\prime} \in \mathcal{V}} \sum_{l \in \mathcal{J}_{v^{\prime}}} T_{l v^{\prime}} r_{i l v^{\prime}}^{-\varepsilon \sigma}}}_{\mu_{i}} \cdot \underbrace{\frac{T_{j v} r_{i j v}^{-\varepsilon \sigma}}{\sum_{v^{\prime} \in \mathcal{V}} \sum_{l \in \mathcal{J}_{v^{\prime}}} T_{l v^{\prime}} r_{i l v^{\prime}}^{-\varepsilon \sigma}}}_{\lambda_{i j v \mid a d o p t}} \\
& =\mu_{i} \cdot \lambda_{i j v \mid \text { adopt }}
\end{aligned}
$$

Conditional on buying, all $i$-specific variables drop out of the choice probability. Imposing the iceberg assumption for transport costs between farmer $i$ and location $v$, we can write:

$$
\lambda_{i j v \mid a d o p t}=\frac{T_{j v} r_{j v}^{-\varepsilon_{a}} \tau_{i v}^{-\varepsilon_{a}}}{\sum_{v^{\prime} \in \mathcal{V}} \sum_{l \in \mathcal{J}_{v^{\prime}}} T_{l v^{\prime}} r_{l v^{\prime}}^{-\varepsilon_{a}} \tau_{i v^{\prime}}^{-\varepsilon_{a}}}
$$

where $\varepsilon_{a}=\varepsilon \sigma$. Since trade costs are specific to location, not agrovet, we can pull the iceberg cost out of the sum across agrovets at each location:

$$
\lambda_{i j v \mid a d o p t}=\frac{T_{j v} r_{j v}^{-\varepsilon_{a}} \tau_{i v}^{-\varepsilon_{a}}}{\sum_{v^{\prime} \in \mathcal{V}} \tau_{i v^{\prime}}^{-\varepsilon_{a}} \sum_{l \in \mathcal{J}_{v^{\prime}}} T_{l v^{\prime}} r_{l v^{\prime}}^{-\varepsilon_{a}}}
$$

Finally, we can rearrange in the form of two probabilities: the probability of buying from some agrovet in location $v$, and then conditional on $v$, the probability of buying at agrovet $j$ within $v$. Precisely:

$$
\lambda_{i j v \mid \text { adopt }}=\underbrace{\frac{\tau_{i v}^{-\varepsilon_{a}} \sum_{l \in \mathcal{J}_{v}} T_{l v} r_{l v}^{-\varepsilon_{a}}}{\sum_{v^{\prime} \in \mathcal{V}} \tau_{i v^{\prime}}^{-\varepsilon_{a}} \sum_{l \in \mathcal{J}_{v^{\prime}}} T_{l v^{\prime}} r_{l v^{\prime}}^{-\varepsilon_{a}}}}_{\lambda_{\text {iv|adopt }}} \cdot \frac{T_{j v} r_{j v}^{-\varepsilon_{a}}}{\sum_{l \in \mathcal{J}_{v}} T_{l v} r_{l v}^{-\varepsilon_{a}}}
$$

To characterize this probability, we will be estimating a functional form for trade costs, the elasticity $\left(\varepsilon_{a}\right)$, and then also a vector of $T_{l v}$ 's. We address each component in order.

\subsection{Calibrating the Farmer's Problem}

\section{Estimating Transport Costs through Location Choice}

The adopt-location-agrovet decomposition detailed above is helpful in that for two of those stages, we have accurate measures of the probability in question for a large portion of the random sample of farmers. Adoption probabilities, $\mu_{i}$, which we will use later, are measured extensively within each village. More novel is our measurement of bilateral probabilities for choosing a particular location to purchase from some agrovet, $\lambda_{i v \mid a d o p t}$. While farmers had a somewhat difficult time recalling the exact agrovet they went to for inputs, in most cases they recalled the location (village) in which the agrovet was located. We now exploit this data to estimate transport costs, as revealed by location choices.

To begin, within a location $v$, we can construct the following index that measures the "return" 
of buying inputs at this location, not including the costs of transport:

$$
\phi_{v}=\sum_{l \in \mathcal{J}_{v}} T_{l v} r_{l v}^{-\varepsilon_{a}}
$$

Essentially, this is similar to a transformation of an inverse price index, but not accounting for trade costs. These $\phi_{v}$ 's are integrated into the choice probability for location $v$ as follows:

$$
\lambda_{i v \mid a d o p t}=\frac{\tau_{i v}^{-\varepsilon_{a}} \phi_{v}}{\sum_{v^{\prime} \in \mathcal{V}} \tau_{i v^{\prime}}^{-\varepsilon_{a}} \phi_{v^{\prime}}}
$$

To estimate equation (20), we need a dataset that identifies when each farmer $i$ chooses location $v$ to purchase fertilizer. Thus, defining $\mathcal{I}$ as the set of farmers who adopt adoption, and $\mathcal{V}$ as the set of locations with an agrovet, we construct a $\mathcal{I} X \mathcal{V}$ dataset of bilateral visit indicators. There will be many zeros in this dataset. For each bilateral combination, we will also measure distance between the farmer's village and the potential purchase location.

Exponentiating the village share equation, and re-writing $\log \left(\phi_{v}\right)$ into a location $v$ fixed effect, $d_{v}$, we can write:

$$
\lambda_{i v \mid a d o p t}=\frac{\exp \left(d_{v}-\varepsilon_{a} \log \left(\tau_{i v}\right)\right)}{\sum_{v^{\prime} \in \mathcal{V}} \exp \left(d_{v^{\prime}}-\varepsilon_{a} \log \left(\tau_{i v^{\prime}}\right)\right)}
$$

As the main objective from this section is to assess the role of trade costs in agrovet choice (and consequently, adoption), we need to specify a functional form for trade costs, $\tau_{i v}$. As a starting point, we will estimate a simple linear relationship between the elasticity adjusted log trade cost and distance, with dummy variables for whether location $v$ is outside the village's urban or rural market-catchment areas:

$$
-\varepsilon_{a} \log \left(\tau_{i v}\right)=\beta_{\text {dist }} \text { dist }_{i v}
$$

Here, dist ${ }_{i v}$ is the kilometer distance between farmer $i$ and location $v$.

To allow for a potentially non-linear cost of travel for farmers by distance (for example, if required technologies differ at longer distance), we will also use distance bins $D_{i v}^{h}$, which are equal to one if the distance between $i$ and $v$ is in bin $h$, and zero otherwise. These will be used as the primary specification as follows:

$$
-\varepsilon_{a} \log \left(\tau_{i v}\right)=\sum_{h} \beta_{h} D_{i v}^{h}
$$

With the distance bins, the multinomial logit is written as:

$$
\lambda_{i v \mid a d o p t}=\frac{\exp \left(d_{v}+\sum_{h} \beta_{h} D_{i v}^{h}\right)}{\sum_{v^{\prime} \in \mathcal{V}} \exp \left(d_{v^{\prime}}+\sum_{h} \beta_{h} D_{i v^{\prime}}^{h}\right)}
$$


These cost estimates will include more than just the monetary costs of travel - there may be other hassle/search costs associated with fertilizer purchases, and the distance bins will absorb these aspects of the farmer decision problem as well.

Equation (23) can be estimated by McFadden's alternative-specific conditional logit. The results from doing so are presented in Table 7 . In the first column, we present the linear specification of distance. Assuming $\varepsilon_{a} \approx 5$ (which will be supported by later results), the results suggest that iceberg transport costs for fertilizer are $3.4 \%$ ad-valorem per kilometer. As technologies may change discretely depending on the distance to each agrovet (walking short distances, taking transit for long distances), our preferred specification using distance bins is presented in column 2 of Table 7. The estimates suggest costly travel for farmers acquiring fertilizer. To interpret the coefficients, we take two approaches. In the first, we can compare two locations with the same "return" from fertilizer, $d_{v}$, and then focus on the reduction in probability if one is $(0,5] \mathrm{km}$ way rather than $0 \mathrm{~km}$ away (essentially in the same village). In this case, the probability that one chooses the location $(0,5] \mathrm{km}$ away compared to 0 km away (in the home village) for idiosyncratic reasons that overcome trade costs is 0.2519

We can also interpret the results as log changes in trade costs via:

$$
\log \left(\tau_{i v}\right)=-\frac{1}{\varepsilon_{a}} \sum_{h} \beta_{h} D_{i v}^{h}
$$

Dividing the coefficient estimates by $\varepsilon_{a}$ give us the log change in trade costs. Given the iceberg assumption, this is also interpreted as the log change in the delivered price. Thus, at the central estimate of $\varepsilon_{a} \approx 5$, the comparison is equivalent to a $6.4 \%$ ad-valorem trade cost per $\mathrm{km}$ (measured at $5 \mathrm{~km}$ ). Using the upper bound of each bin as a conservative measure to calculate ad-valorem trade costs, the ad-valorem equivalent rises modestly over the next few bins - for example, choosing an agrovet 15-20km away, the approximate ad-valorem equivalent trade cost evaluated at the upper cutoff is $7.2 \%$ per $\mathrm{km}$.

Finally, we repeat the exercise from the reduced form section of the paper and calculate best trade-cost-adjusted-prices for agrovets for all villages in the region, using the estimates of iceberg costs as described above. These results are presented in Figure 3. Here, there is significantly more heterogeneity in best trade cost adjusted prices for fertilizer, which suggests sizable non-pecuniary costs of traveling to acquire fertilizer.

\section{Calibrating Non-price Attributes of Each Agrovet}

In the conditional multinomial logit used above, if enough farmers were sampled such that every location with an agrovet was chosen, it would be possible to estimate precisely a value of $\phi_{v}$ for each

\footnotetext{
${ }^{19}$ This is calculated precisely by calculating the ratio of probabilities:

$$
\frac{\lambda_{0-5 k m}}{\lambda_{0 k m}}=\frac{\exp \left(d_{v}-1.38\right)}{\exp \left(d_{v}-0\right)}=0.25
$$
}


location (up to the usual normalization), and use this in resulting counterfactuals. Unfortunately, funding was not sufficient to survey such a large sample, and thus, to recover all non-price attributes of all locations that contain an agrovet, we must employ a combination of agrovet revenue shares from our agrovet survey, and the spatial distribution of fertilizer expenditures from the farmer survey.

To derive a market-clearing condition that we intend to calibrate, we start from an equation that summarizes expected agrovet sales as aggregated from spatial farmer-level demand. Defining expected agrovet sales at $j$ in $v$ as $\mathbb{E}\left[v_{j v}\right]$, we have:

$$
\mathbb{E}\left[v_{j v}\right]=\sum_{i} L_{i} \mu_{i} \lambda_{i j v \mid a d o p t} \mathbb{E}\left[F_{i} \mid \text { adopt at } j v\right]
$$

where $\mathbb{E}\left[F_{i} \mid\right.$ adopt at $\left.j v\right]$ is expected fertilizer expenditures by $i$, conditional on adopting at $j v$, and $L_{i}$ is the village population to use as weights in the demand equation. Noting that $\mu_{i}=$ $\frac{\mathbb{E}\left[F_{i}\right]}{\mathbb{E}\left[F_{i} \mid \text { adopt }\right]}$, which is the ratio of the unconditional expected expenditures on fertilizer to the expected expenditures on fertilizer, given adoption, we can write:

$$
\mathbb{E}\left[v_{j v}\right]=\sum_{i} L_{i} \lambda_{i j v \mid \text { adopt }} \frac{\mathbb{E}\left[F_{i} \mid \text { adopt at } j v\right]}{\mathbb{E}\left[F_{i} \mid \text { adopt }\right]} \mathbb{E}\left[F_{i}\right]
$$

Using the properties of the Fréchet distribution, it is straightforward to show that $\frac{\mathbb{E}\left[F_{i} \mid \text { adopt at jv] }\right.}{\mathbb{E}\left[F_{i} \mid \text { adopt }\right]}=$ 1 ; that is, the expected expenditures conditional on adoption anywhere is the same as the expected expenditures at some $j$, conditional on choosing $j 20$ Thus, we have:

$$
\mathbb{E}\left[v_{j v}\right]=\sum_{i} \lambda_{i j v \mid a d o p t} \mathbb{E}\left[F_{i}\right]
$$

Imposing the definition of $\lambda_{i j v \mid a d o p t}$ :

$$
\mathbb{E}\left[v_{j v}\right]=\sum_{i} L_{i}\left(\frac{T_{j v} \tau_{i v}^{-\varepsilon_{a}} r_{j v}^{-\varepsilon_{a}}}{\sum_{v^{\prime} \in \mathcal{V}} \sum_{l \in \mathcal{J}_{v^{\prime}}} T_{l v^{\prime}} \tau_{i v^{\prime}}^{-\varepsilon_{a}} r_{l v^{\prime}}^{-\varepsilon_{a}}}\right) \mathbb{E}\left[F_{i}\right]
$$

Finally, we can combine the agrovet-specific non-price attributes and the price into an "agroveteffect" $\left(\eta_{j v} \equiv T_{j v} r_{j v}^{-\varepsilon_{a}}\right)$, and also impose the specification for transportation costs, to get:

$$
\mathbb{E}\left[v_{j v}\right]=\sum_{i} L_{i}\left(\frac{\exp \left(-\sum_{h} \beta_{h} D_{i v}^{h}\right) \eta_{j v}}{\sum_{v^{\prime} \in \mathcal{V}} \sum_{l \in \mathcal{J}_{v^{\prime}}} \exp \left(-\sum_{h} \beta_{h} D_{i v^{\prime}}^{h}\right) \eta_{l v^{\prime}}}\right) \mathbb{E}\left[F_{i}\right]
$$

To implement this equation, we use observed agrovet fertilizer revenues for each agrovet to proxy for $\mathbb{E}\left[v_{j v}\right]$, and village-level fertilizer expenditures from the farmer's survey to proxy for $\mathbb{E}\left[F_{i}\right]$. That is, for this equation, we take $i$ to represent villages and sum up expenditures within each village.

However, we again run into an number of issues where our farmer survey was not large enough

\footnotetext{
${ }^{20}$ See technical appendix for a proof
} 
to survey farmers from every village in the region, and the population of farmers within each village. To this end, there are two issues to consider. First, within each village, while we surveyed approximately 16 maize farmers per village, in some villages zero or full adoption is reported. In reality, this may be accurate, or may be biased toward the bounds by a small sample. Further, village adoption at the bounds will also complicate the calibration of the overall adoption decision (which we describe in a moment). To facilitate a feasible calibration that is consistently applied across market clearing conditions and the adoption decision, we first winsorize the village adoption data to fall between 0.025 and $0.975{ }^{21}$ Then, for those villages that report zero adoption in the sample, we assign a small value of $\mathbb{E}\left[F_{i}\right]$ that is calculated via the model using the reported land holdings of the village in the sample, the winsorized adoption share (0.025), and then the 1st percentile value of fertilizer expenditures per acre of land across the entire sample of farmers who adopt, $\left(\frac{F_{i}}{K_{i}}\right)_{1} 22$

Focusing on the sampling of villages, if we assume that the farmer sample captures the entire geography of demand, there will exist agrovets in other locations that appear more remote than they actually are since no farmers were surveyed in that location. This will cause a bias in estimates of $\eta_{j v}$ 's by assigning a large value for agrovet locations without any farmers surveyed to make-up for the incorrectly assigned remoteness. At present, the only solution to this problem is to assume that all villages within a market-catchment area share the same characteristics as the (one) surveyed village in that area. Since village selection within a market catchment area was random, this should only add random measurement error to the village $i$ observables that are used in the calibration.

Two other empirical issues to consider are more straightforward. Since agrovet fertilizer revenues and farmer expenditures are from different surveys, and the latter aggregated from a farmer level sample, we normalize each to sum to one. After doing so, we can recover $\eta_{j v}$ by solving the nonlinear system of equations formed using $\mathcal{J}$ agrovets and their revenue shares, as written in (29), under the normalizing assumption that $\sum_{v} \sum_{j} \eta_{j v}=1{ }^{23}$ Then, after recovering the $\eta_{j v}$ 's, we calibrate the value of $\varepsilon_{a}$ using the following regression (based on $\eta_{j v}=T_{j v} r_{j v}^{-\varepsilon_{a}}$ ):

$$
\log \left(\eta_{j v}\right)=-\varepsilon_{a} \log \left(r_{j v}\right)+\underbrace{\beta \operatorname{exper}_{j v}+\text { district }+u_{j v}}_{\log \left(T_{j v}\right)}
$$

where $\log \left(T_{j v}\right)$ will be recovered as the components of the regression not equal to the elasticityadjusted log agrovet price. To account for other local factors that may be correlated with prices and location quality, we include agrovet-level experience at that location, exper ${ }_{i v}$, and district fixed effects. Running this regression, instrumenting for current agrovet prices with one-year lagged

\footnotetext{
${ }^{21}$ This effectively means that villages with zero adoption in the sample are assigned a level of adoption $50 \%$ lower than the lowest observed (positive) adoption share in the sample. Or, alternatively, that we would need to double the within-village sample size to find one farmer who adopts.

${ }^{22}$ Precisely, imputed (small) values for expected fertilizer expenditures are calculated by: $\mathbb{E}\left[F_{i}\right]=0.025\left(\frac{F_{i}}{K_{i}}\right)_{1} \cdot K_{i}$

${ }^{23}$ This normalizing assumption is required since the probabilities within the sum in equation 29$]$ are homogeneous degree zero in $\eta$ 's.
} 
prices, yields an estimate of $\varepsilon_{a}=5.1424$

\section{Calibrating Adoption}

For the final part of the farmers problem, we work to recover the (relative) productivity of not using fertilizer for each village, $T_{i 0}$. To begin, recall that the probability of adoption is written as:

$$
\mu_{i}=\frac{\sum_{v^{\prime} \in \mathcal{V}} \sum_{l \in \mathcal{J}_{v^{\prime}}} T_{l v^{\prime}} \tau_{i v^{\prime}}^{-\varepsilon_{a}} r_{l v^{\prime}}^{-\varepsilon_{a}}}{\Phi_{i 0} T_{i 0}\left(\frac{\pi_{i 0}}{\pi_{i}}\right)^{\varepsilon}+\sum_{v^{\prime} \in \mathcal{V}} \sum_{l \in \mathcal{J}_{v^{\prime}}} T_{l v^{\prime}} \tau_{i v^{\prime}}^{-\varepsilon_{a}} r_{l v^{\prime}}^{-\varepsilon_{a}}}
$$

where $\Phi_{i 0}=T_{i 0}\left(\frac{\pi_{i 0}}{\pi_{i}}\right)^{\varepsilon}=T_{i 0} p_{i}^{\varepsilon_{p}} w_{i}^{\varepsilon_{w}} \varepsilon_{p}=\varepsilon\left(\frac{\alpha-\alpha_{0}}{\alpha \alpha_{0}}\right)$ and $\varepsilon_{w}=\varepsilon\left(\beta \frac{1-\alpha}{\alpha}-\frac{1-\alpha_{0}}{\alpha_{0}}\right)$. Using the imputed adoption shares for each village (as described in the preceding section), we recover $\Phi_{i 0}$ s by inverting equation (31).

Beyond calibrating the term related to non-adoption, $\Phi_{i 0}$, the elasticities of adoption with respect to price and wages will depend on the values of the parameters of the Cobb-Douglas production functions with and without fertilizer. For assessing basic input counterfactuals and quantifying the impact of remoteness on adoption, these production function estimates are not required. However, they will be required for mark-up calculations to calibrate the agrovet pricing equilibrium; specifically, separating the substitution elasticity $\varepsilon_{a}$ from the native distribution parameter $\varepsilon$. In the appendix, we detail a simple estimator for maize production with and without fertilizer, and using the Tanzanian LSMS, produce estimates for $\alpha$ (0.431) and $\alpha_{0}$ (0.570). Also using the LSMS, we use reported wages and labor and fertilizer expenditures to calculate the share of labor in variable factors; $\beta$ (0.75). Using these estimates, it is straightforward to calculate that $\varepsilon=14.96$. While this may seem high, this essentially means that there is little idiosyncratic variation in quality-adjusted prices at each agrovet, around the $T_{j v}$ 's. Practically, farmers are choosing the lowest quality adjusted price for each agrovet, with minimal other variation that distracts from prices, quality, and transport costs.

\section{Agrovet Pricing and Markups}

In the farmers problem, adoption was a function of a quality-adjusted delivered price for fertilizer at each agrovet option, as well as other terms that represent the relative incentives to abstain from using fertilizer. When we evaluate various trade shocks, we could do so while holding agrovet prices fixed. However, while this might be fine for local shocks, for a larger trade shock, such as a roads program, allowing for retail prices and mark-ups to change is crucial for a realistic counterfactual. We now derive the pricing problem for agrovets, and describe the calibration for mark-ups (which is similar to Berry, 1994).

\footnotetext{
${ }^{24}$ The first stage F-statistic for weak instruments is 304.147 , and the Wu-Hausman test statistic for endogeneity is 0.001 (p-value 0.981), suggesting this IV approach is sound.
} 
As is well-known, the first order condition for an oligopolist is a mark-up over marginal cost:

$$
r_{j v}=\frac{\varepsilon_{j v}^{d}}{\varepsilon_{j v}^{d}+1} c_{j v}
$$

where $c_{j v}$ is the marginal cost for agrovet $j$ in location $v$, and $\varepsilon_{j v}^{d}$ is the elasticity of agrovet $j$ demand with respect to it's own price. Defining $\varepsilon_{j v}^{v}$ as the elasticity of revenue with respect to its own price, we have:

$$
r_{j v}=\frac{\varepsilon_{j v}^{v}-1}{\varepsilon_{j v}^{v}} c_{j v}
$$

Defining $s_{i j v}=\frac{\lambda_{i j v \mid \text { adopt }} \mathbb{E}\left[F_{i}\right]}{\sum_{i^{\prime}} \lambda_{i^{\prime} j v \mid \text { adopt }} \mathbb{E}\left[F_{i^{\prime}}\right]}$ as the expenditure share on $i$ within $j v$, in the technical appendix we derive the following:

$$
\varepsilon_{v}=-\varepsilon_{a}+\frac{\varepsilon-1}{\varepsilon} \varepsilon_{a} \sum_{i} s_{i j v} \lambda_{i j v}
$$

This elasticity equation provides clear intuition regarding the spatial distribution of demand, market power and mark-ups. For each firm, $\sum_{i} s_{i j v}=1$, and thus, variation in mark-ups depends on the unconditional probability of a farmer from village $i$ choosing agrovet $j$ in village $v$. When firms are "small" within the context of the market, $\lambda_{i j v} \approx 0$ for all $i$ and the mark-up is pinned down by the substitution across agrovets through the elasticity, $\varepsilon_{a}$.

Using this elasticity formula calculated for each agrovet, we can then solve for the revealed marginal cost of selling fertilizer by using the mark-up equation. The predicted markups have a mean of 0.2164 (median $=0.2018$ ), which while lower is not remarkably different from the measured mark-ups in the reduced form $($ mean $=13 \%)$

\section{Counterfactuals}

In this section, we use the calibrated and estimated parameters to evaluate a number of counterfactuals on input and output market access. To solve for the counterfactuals, we simply solve for a new vector of fertilizer prices that solves the first order conditions in $(32)$, while taking into account equilibrium changes in the farmers problem in response to new agrovet prices and/or trade costs.

\subsection{Experiments on Input Access}

We begin by focusing on the effects of local access to fertilizer on adoption decisions. A general hypothesis that we have developed in the paper is that farmers are likely disadvantaged if agrovets are not in close proximity. While a number of villages have an agrovet at that location, many do not, and in some cases have to travel non-trivial distances to acquire fertilizer and other inputs. We study these issues in two ways: reduction in transport costs, and effects of agrovet entry. 


\section{Transportation Costs}

To study the role of access to inputs using a realistic counterfactual, we appeal to Casaburi, Glennerster and Suri (2013) and evaluate the effects of a 50\% reduction in iceberg costs through a hypothetical roads improvement program. Such a cost reduction can also be motivated by local speeds on trunk roads in Kilimanjaro being approximately $50 \%$ lower than US speed (according to Google Maps). The results of this counterfactual in terms of adoption by each village are displayed in the top-left panel of Figure 4. The bottom left panel reports the effects on log fertilizer expenditures within each village. For clarity, we have grouped villages into 20 equally sized bins of standardized remoteness, and the points in the Figure represent average adoption within these groups. For interpretation, we have also plotted lines of best fit when regressing baseline or counterfactual adoption (or expenditures) on remoteness. For these regressions, we use the raw village data rather than binned.

In the top left panel, we find a large adoption effect of $28 \mathrm{pp}$, or approximately twice baseline. This counterfactual alone accounts for $18 \%$ of the adoption-remoteness relationship at baseline. The results for expenditures are even more pronounced, where expenditures rise approximately $1.35 \log$ points, though it is important to keep in mind that for many villages we are moving from an extremely low base. Nevertheless, the log-expenditure-remoteness gradient is cut in half by this counterfactual. Thus, we conclude that holding local factors fixed, access to input markets has a large effect on adoption levels, and contributes substantially to the reduced adoption levels in remote areas.

Also on the input side, we evaluate how the costs for retailers to source inputs from distributors affects the adoption decision. Through our detailed agrovet surveys, as summarized in the reduced form, we document that the costs of sourcing inputs from distributors rises significantly with distance from Moshi. So, in the second counterfactual, we subsidize this cost by $50 \%$. The effects of this counterfactual are presented in the top-right panel of Figure 4. Here, adoption rises by about $1 \mathrm{pp}$, or $4.4 \%$, and yields a $4 \%$ reduction in the remoteness-adoption gradient. Thus, although effects on levels are modest, the effect of this subsidy on the remoteness gradient, despite any absorption by mark-ups, is non-trivial.

\section{Entry}

An overarching question throughout the paper has been why agrovet access is worse in rural areas, and in particular, why agrovets enter intensely in other areas. While we do not present an empirical model of entry (for example, as in Seim, 2006), we do run a simple counterfactual to examine profitability of entry and any corresponding effects on adoption. Specifically, we force a "median" agrovet (as defined by $T_{j v}$ and marginal cost, within a district) to enter every village in the sample (one at a time, not simultaneously), and then measure the effects of that singular entry on adoption, and also measure the profitability of the entrant after entry. We do this for every village in the dataset, and then plot in the top panel of Figure 5 aggregate adoption (after entry) and entrant profits as a function of distance to the village in which the entry took place. Very clearly, profits 
are higher when entering less remote villages, though adoption effects are also higher when entering the more remote villages. The former relationship is particularly strong, where a one standard deviation increase in remoteness reduces the profitability of hypothetical entry by 0.35 log points. Thus while access to agrovets in remote areas would improve adoption more so than entering lessremote areas, the profitability analysis supports the argument that this lack of entry in remote areas is logical.

\subsection{Experiments in Output Access}

Also summarized in the reduced form, more remote villages tend to travel farther to reach their primary market, and these travel costs can reduce the margin available to selling their maize harvest. Further, in the reduced form, the optimally chosen "best" travel-cost adjusted selling prices are negatively correlated with remoteness. Subject to a number of caveats described below, we now examine both margins on the output side and their effects on adoption.

First, as in the reduced form exercises, we assume as that farmers optimally choose the best market to sell, subject to the measured/estimated costs of transportation from village to village. We measure the baseline best net-selling price, and then recalculate this best net-selling price after reducing transportation costs by $50 \%$. With the baseline and counterfactual net selling price, the

shock that is relevant to the model for each farmer is $\Phi_{i 0}\left(\frac{p_{i c}}{p_{i 0}}\right)^{\varepsilon_{p}}$, where the ratio of counterfactual prices $p_{i c}$ to baseline output prices $p_{i 0}$ is interacted with the original calibrated parameter and raised to the price-elasticity $\varepsilon_{p}$. The results of this counterfactual shock are presented in the bottom left panel of Figure 5. Here, we see an adoption-remoteness gradient that is cut by a similar amount to the input market counterfactuals, and an adoption effect that is about 0.2 , or $65 \%$. Thus, this counterfactual has a lower effect on adoption when compared with a $50 \%$ cut in farmer-retailer transport costs, but a similar effect on the gradient. However, care must be taken in comparing the two. In the case of the cut in farmer-retailer transport costs, the transport cost cut is interacted with prices and calibrated agrovet quality terms, which adds noise to the shock. That is, while a farmer might be more likely to travel to any agrovet, the transport shock is not concentrated on the agrovet that is closest or that the farmer will necessarily choose. In contrast, the best net selling price is determined by a simple calculation of the maximum net price, with no probability of choosing different option. Thus, the noise in the farmer-retailer transport shock as it relates to distance will attenuate its effect on the gradient, though still provide a sizable effect on adoption.

Keeping in mind the same caveat for our final counterfactual, we now assume that farmers sell at their closest market, and experience a 50\% reduction in iceberg costs to that market, as estimated by the agrovet choice problem. That is, the farmer must ship $\tau_{i m}$ units of maize to the market to effectively sell one unit. Thus the transport-adjusted selling price that we use for each village above when calibrating adoption decisions is equal to $p_{i}=p_{m} / \tau_{i m}$, where $p_{i}$ is net selling price to farmer $i$ and $p_{m}$ is the price at the primary market for that village. To examine the impact of output market access on adoption, we now run an experiment cutting the iceberg costs to reach output markets by $50 \%$. The results from this counterfactual are presented in the bottom-right 
panel of Figure 5. Here, adoption almost doubles, and the adoption-remoteness gradient falls by about $30 \%$.

Overall, access to output markets appears to be an important component of the input adoption decision, and these effects deserve more detailed attention in follow-up work that more rigorously documents the movement of maize from the plot to the market and beyond.

\section{$7 \quad$ External validity}

While our data collection spans a large portion of Northern Tanzania, our datais still limited to only one region in one country. Do our results generalize? While we cannot provide a definitive answer, we provide some suggestive evidence in this section.

\subsection{Price Dispersion}

To address this, we assembled five secondary dataset: ${ }^{25}$ across 1,512 locations ${ }^{26}$ in 56 African countries. We compare this to a small dataset we assembled between March and April 2016 with 251 retailers of various sorts (shops, agro-input dealers, and maize traders) in 82 markets in the Kilimanjaro region 27 To quantify price dispersion, we first decompose variation in spatial prices by running the following regression:

$$
\log \left(p_{m c j t}\right)=\gamma_{c}+\gamma_{j}+\gamma_{t}+\epsilon_{m j t}
$$

where $p_{m j t}(\log )$ prices in market $m$ for product $j$ at time $t$ in country $c$, and the $\gamma$ terms are country, product, and time fixed effects. We calculate the standard deviation of the resulting residual. Results are reported in Web Appendix Table A5. In the secondary datasets, the standard deviation is 0.45 for all products, 0.34 for maize, and 0.12 for fertilizer; in our Tanzania data, the figures are $0.22,0.14$, and 0.09. The somewhat lower standard deviation in our data could be indicative of reduced measurement error, or that prices vary less within the geographic concentrated area of Kilimanjaro. Nevertheless, price dispersion is substantial within Kilimanjaro as well.

We also follow the literature ${ }^{28}$ to run dyadic regressions to look at price gaps, as follows:

\footnotetext{
${ }^{25}$ We include the following datasets: (1) prices of 6 staple crops in 41 major market centers in 8 East African countries from 1997-2015, collected by RATIN; (2) prices of 25 commodities from 276 markets in 53 countries in from 2013-2015, collected by Africafoodprices.io; (3) prices of 4 major varieties of fertilizer (Urea, DAP, CAN, and NPK complex 17-17-17) in 129 markets in 7 East African countries collected by AMITSA; (4) prices of 5 major varieties of fertilizer (Urea, CAN, DAP, and NPK 1717 17) in 18 countries from 2010-16 in Africafertilizer.org; and (5) prices of a number of commodities in 38 countries from 1992-2016 collected by the WFP.

${ }^{26}$ These are not necessarily all unique locations. Though we have cleaned these datasets, there are some misspellings, different names for the same markets, and also differing levels of granularity in the datasets.

${ }^{27}$ To enroll participants, we visited each market and selected several types of retailers for project inclusion, including fertilizer retailers ("agrovets"), maize sellers, and retail shops. Each respondent was called once per month and asked about current retail and wholesale prices for each item in a pre-selected list of standardized goods (e.g., $200 \mathrm{ml}$ box of Azam juice). Respondents were compensated for participation by mobile money transfer.

${ }^{28}$ See Engel and Rogers (1996). In addition, see papers on the effect of cell phones on price dispersion, for example Aker (2010), Aker and Fafchamps (2015), and Jensen (2007).
} 


$$
\log \left(\left|p_{m j t}-p_{m^{\prime} j t}\right|\right)=\theta \log \left(c_{m m^{\prime}}\right)+\gamma_{m}+\gamma_{m^{\prime}}+\gamma_{j}+\epsilon_{m m^{\prime} j t}
$$

where $p_{m j t}-p_{m^{\prime} j t}$ is the price gap between markets $m$ and $m^{\prime}$ and $c_{m m^{\prime}}$ is the cost of transport between markets ${ }^{29}$ Results are presented in Web Appendix Table A6. For each dyad, we regress the absolute difference in log prices on two measures of distance: (1) kilometers between locations in Columns 1, 4, and 7, and (2) driving time between locations in Columns 2, 5, and 8 (both calculated via Google Maps API). We cluster standard errors by both the destination and origin market. In each of the secondary datasets, we find significant, positive coefficients, suggesting that price gaps are larger between more distant markets. The coefficients are economically meaningful: a doubling of travel costs would increase price gaps by about 1-3\% in the secondary datasets. In Tanzania, we find that doubling distances would increase price gaps by a similar amount. Finally, we can use this data to provide some descriptive evidence on road upgrading. We conjecture that price gaps should respond to the time it takes to travel from point to point, and not the geographic distance (since the time and other costs of traveling to sell items should be what is important). To examine this, we regress price gaps on both distance and duration in Columns 3, 6, and 9. Consistent with priors, we find that duration is significant, whereas distance is not - which suggests that improving road quality would reduce these gaps.

\subsection{Fertilizer adoption}

In Web Appendix Table A7, we assembled data from the World Bank LSMS-ISA household panel surveys for Ethiopia, Niger, Nigeria, Malawi, Tanzania, and Uganda, to study how remoteness affects fertilizer adoption. In the LSMS, measures of remoteness include distance to the main market, and distance to a population center. Using both measures of remoteness, we find a negative association between remoteness and technology adoption.

\section{Conclusion}

In this paper we collect detailed data on transportation costs, input and output prices, and the intensive and extensive margins of input purchases and output sales from market actors across the entirety of the supply chains for maize and fertilizer in all 1,183 villages in the Kilimanjaro and Manyara regions of Northern Tanzania. This data enables us to document large heterogeneity in market access, and study its implications for prices and for market participation. We find that there is large variation in prices, and that the most remote villages face prices substantially higher than the least remote (equivalent to about $40 \%$ of the mean). The rates and magnitudes of fertilizer use and maize sales also display a large and significant distance gradient. Counterfactuals on the input and output sides suggest an important role for lowering access barriers on the input side for reducing this gradient, and a more qualified one for those on the output side.

\footnotetext{
${ }^{29}$ These regressions are motivated by an assumption of free entry where an arbitrageur will enter if $\left|\left(p_{m}-p_{m^{\prime}}\right)\right| \geq$ $c_{m m^{\prime}}$. While we know that free entry is not realistic in this context, we reproduce these results for comparability.
} 
The results of these counterfactuals lead directly to the question of policy implications. Many African countries have experimented with input subsidies (some intermittently, and some more consistently), and these have had large adoption and usage effects by directly lowering the delivered price of fertilizer even though the transport cost may have stayed unaffected. However, most farmers fail to graduate out of the subsidy for a host of reasons, potentially including the fact that the market access issues remain unresolved. Therefore, policies that lower fertilizer prices through reducing transport costs can potentially have lasting effects, such as improving transportation linkages between markets and villages, and also between urban centers and villages. Initiatives to organize farmers into cooperative groups that enable them to defray the total costs of transportation over a large number of buyers may also be helpful. 


\section{References}

[1] Adukia, Anjali, Sam Asher, and Paul Novosad (2016). "Educational Investment Responses to Economic Opportunity: Evidence from Indian Road Construction." Unpublished.

[2] Aggarwal, Shilpa (2018a). "Do Rural Roads Create Pathways out of Poverty? Evidence from India." Journal of Development Economics 133: 375-395.

[3] Aggarwal, Shilpa (2018b). "The Long Road to Health: Healthcare Utilization Impacts of a Road Pavement Policy in Rural India." Unpublished

[4] Aggarwal, Shilpa, Eilin Francis, and Jonathan Robinson (2018) "Grain Today, Gain Tomorrow: Evidence from a Storage Experiment with Savings Clubs in Kenya," Journal of Development Economics 134: 1-15.

[5] Alder, Simon (2017). "Chinese Roads in India: The Effect of Transport Infrastructure on Economic Development." Unpublished.

[6] Allen, Treb and Costas Arkolakis (2016). "The Welfare Effects of Transportation Infrastructure Improvements." Unpublished.

[7] Asher, Sam and Paul Novosad (2016). "Market Access and Structural Transformation: Evidence from Rural Roads in India." Unpublished.

[8] Asturias, Jose, Manuel Garcia-Santana, and Roberto Ramos (2017). "Competition and the welfare gains from transportation infrastructure: Evidence from the Golden Quadrilateral of India." Unpublished.

[9] Atkin, David and David Donaldson (2015). "Who's Getting Globalized? The Size and Implications of Intra-National Trade Costs." NBER Working Paper No. 21439

[10] Banerjee, Abhijit, Esther Duflo, and Nancy Qian (2012). "On the Road: Access to Transportation Infrastructure and Economic Growth in China," Unpublished.

[11] Beaman, Lori, Dean Karlan, Bram Thuysbaert, and Christopher Udry (2013). "Profitability of Fertilizer: Experimental Evidence from Female Rice Farmers in Mali." American Economic Review 103 (3): 381-86.

[12] Bergquist, Lauren (2017). "Pass-Through, Competition, and Entry in Agricultural Markets: Experimental Evidence from Kenya." Unpublished.

[13] Bergquist, Lauren, Marshall Burke, and Edward Miguel (2017). "Selling Low and Buying High: an Arbitrage Puzzle in Kenyan Villages." Unpublished.

[14] Berry, Steven (1994). "Estimating Discrete-Choice Models of Product Differentiation." RAND Journal of Economics 25 (2): 242-262.

[15] Bird, Julia and Stephane Straub (2014). "The Brasilia experiment: road access and the spatial pattern of long-term local development in Brazil." Unpublished. 
[16] Casaburi, Lorenzo and Tristan Reed (2017). "Competition in Agricultural Markets: An Experimental Approach." Unpublished

[17] Chatterjee, Shoumitro (2018). "Market Power and Spatial Competition in Rural India." Unpublished.

[18] Costinot, Arnaud and Andres Rodriguez-Clare (2014). "Trade Theory with Numbers: Quantifying the Consequences of Globalization." In Handbook of International Economics, Volume 4, Chapter 4. Editors: Gita Gopinath, Elhanan Helpman, and Kenneth Rogoff. Elsevier.

[19] Dhingra, Swati and Silvana Tenreyro (2017). "Piggy-Back Exporting, Intermediation, and the Distributional Gains from Trade in Agricultural Markets." Unpublished.

[20] Donaldson, David (2015). "The Gains from Market Integration." Annual Review of Economics 7: 619-647.

[21] Donaldson, David (2018) "Railroads of the Raj: Estimating the impact of transportation infrastructure." American Economic Review 108 (4-5):899-934.

[22] Duflo, Esther, Michael Kremer, and Jonathan Robinson (2008). "How high are rates of return to fertilizer? Evidence from field experiments in Kenya." American Economic Review 98 (2): 482-488.

[23] Eaton Jonathan and Samuel Kortum (2002). "Technology, Geography, and Trade." Econometrica 70: $1741-1779$

[24] Gertler, Paul, Tadeja Gracner, Marco Gonzalez-Navarro, and Alex Rothenberg (2014). "Road Quality and Local Economic Activity: Evidence from Indonesia's Highways." Unpublished.

[25] Ghani, Ejaz, Arti G. Goswami, and William R. Kerr (2016). "Highway to success: The impact of the Golden Quadrilateral project for the location and performance of Indian manufacturing." Economic Journal 126 (591): 317-357.

[26] Hernandez, Manuel and Maximo Torero (2011). "Fertilizer Market Situation. Market Structure, Consumption and Trade Patterns, and Pricing Behavior." International Food Policy Research Institute (IFPRI), Washington, DC, USA.

[27] Khanna, Gaurav (2016). "The Road Oft Taken: The Route to Spatial Development." Unpublished.

[28] Minten, Bart, Bethlehem Koru and David Stifel (2013), "The last mile(s) in modern input distribution: Pricing, profitability, and adoption", Agricultural Economics, Vol 44, pp. 629646

[29] Seim, Katja (2006), "An Empirical Model of Firm Entry with Endogenous Product-Type Choices", The RAND Journal of Economics, 37-3, pp 619-640

[30] Sotelo, Sebastian (2018). "Domestic Trade Frictions and Agriculture." Unpublished.

[31] Storeygard, Adam (2016). "Farther on down the Road: Transport costs, trade and urban growth in Sub-Saharan Africa." Review of Economic Studies 83 (3): 1263-1295. 
[32] Suri, Tavneet (2011). "Selection and Comparative Advantage in Technology Adoption." Econometrica 79 (1): 159-209

[33] World Bank (2008). World Development Report 2008: Agriculture for Development. Washington, DC: World Bank.

[34] World Bank (2010). "Africa's Infrastructure: A time for Transformation." Africa Development Forum. Washington, DC.

[35] World Bank (2017). "Enabling the Business of Agriculture 2017." Washington, DC: World Bank. doi:10.1596/978-1-4648-1021-3. License: Creative Commons Attribution CC BY 3.0 IGO

[36] Yi, Kei-Mu (2003). "Can Vertical Specialization Explain the Growth of World Trade?" Journal of Political Economy 111 (1): 52-102.

\section{A Deriving farmer profits, revenues, and input expenditures}

The production function under basic technology is:

$$
Y_{i}=\widetilde{\theta}_{i 0} K_{i}^{\alpha} L_{i}^{1-\alpha}
$$

Here, $\widetilde{\theta}_{i 0}$ is baseline productivity without technology for farmer $i, K_{i}$ is land held by farmer $i$ (which is assumed to be fixed), and $L_{i}$ is labor hired/used by farmer $i$. Farmers who choose the baseline technology maximize the following profit function:

$$
\Pi_{i 0}=\max _{L_{i}}\left\{p_{i} \widetilde{\theta}_{i 0} K_{i}^{\alpha} L_{i}^{1-\alpha}-w_{i} L_{i}\right\}
$$

where $p_{i}$ is the output price and $w_{i}$ is the local wage. The first-order condition with respect to labor is written as:

$$
(1-\alpha) p_{i} \widetilde{\theta}_{i 0} K_{i}^{\alpha} L_{i}^{-\alpha}=w_{i}
$$

Multiplying both sides of the first order condition by $L_{i}$, it is straightforward to show that expenditures on labor are linked to revenues $\left(R_{i 0}\right)$ and profits $\left(\Pi_{i 0}\right)$ by

$$
w_{i} L_{i}=(1-\alpha) p_{i} \widetilde{\theta}_{i 0} K_{i}^{\alpha} L_{i}^{1-\alpha}=(1-\alpha) R_{i 0}
$$

and substituting into the profit function, we have:

$$
\begin{aligned}
\Pi_{i 0} & =\alpha R_{i} \\
\Rightarrow w_{i} L_{i} & =\frac{1-\alpha}{\alpha} \Pi_{i 0}
\end{aligned}
$$


Thus, labor expenditures are proportional to profits and revenues, a feature that will prove convenient when aggregating the model. Explicitly solving for labor in the first order condition, and substituting into the profit function, we have:

$$
\begin{aligned}
\Pi_{i 0} & =\alpha_{0}\left(1-\alpha_{0}\right)^{\frac{1-\alpha_{0}}{\alpha_{0}}} \widetilde{\theta}_{i 0}^{\frac{1}{\alpha_{0}}} p_{i}^{\frac{1}{\alpha_{0}}} w_{i}^{-\frac{1-\alpha_{0}}{\alpha_{0}}} K_{i} \\
& =\theta_{i 0} \pi_{i 0}
\end{aligned}
$$

Here, we have defined $\theta_{i 0}=\alpha_{0}\left(1-\alpha_{0}\right)^{\frac{1-\alpha_{0}}{\alpha_{0}}} \widetilde{\theta}_{i 0}^{\frac{1}{\alpha_{0}}}$ and $\pi_{i 0}=p_{i}^{\frac{1}{\alpha_{0}}} w_{i}^{-\frac{1-\alpha_{0}}{\alpha_{0}}} K_{i}$. We return to these two terms momentarily when characterizing the adoption decision.

The production function with fertilizer splits variable inputs into labor and acquired fertilizer, $X_{i j v}$, and also provides a productivity shock, $\widetilde{\theta}_{i j v}$, which may vary by the agrovet $j$ location $v$ pair at which the fertilizer is purchased. Precisely, production is written as:

$$
Y_{i}=\widetilde{\theta}_{i j v} K_{i}^{\alpha} L_{i j v}^{(1-\alpha) \beta} X_{i j v}^{(1-\alpha)(1-\beta)}
$$

The profit maximization problem when using fertilizer is written as:

$$
\Pi_{i 0}=\max _{L_{i}, X_{i j v}} p_{i} \widetilde{\theta}_{i j v} K_{i}^{\alpha} L_{i j v}^{(1-\alpha) \beta} F_{i j v}^{(1-\alpha)(1-\beta)}-w_{i} L_{i j v}-r_{i j v} F_{i j v}
$$

Since technology is Cobb-Douglas, including within variable inputs, similar results from above apply here. That is, writing expenditures on variable inputs as $c_{i j v} M_{i j v}$, where $c_{i j v}$ is the unit cost of a bundle of variable inputs $M_{i j v}$, it is easily shown that

$$
c_{i j v} M_{i j v}=(1-\alpha) p_{i} \widetilde{\theta}_{i j v} K_{i}^{\alpha} L_{i j v}^{(1-\alpha) \beta} F_{i j v}^{(1-\alpha)(1-\beta)}=(1-\alpha) R_{i j v}
$$

and

$$
\begin{aligned}
\Pi_{i j v} & =\alpha R_{i j v} \\
\Rightarrow c_{i j v} M_{i j v} & =\frac{1-\alpha}{\alpha} \Pi_{i j v}
\end{aligned}
$$

Further, since labor and fertilizer have $\beta$ and $1-\beta$ share in variable inputs, respectively, expenditures on each input are written as:

$$
\begin{aligned}
w_{i} L_{i j v} & =\beta \frac{1-\alpha}{\alpha} \Pi_{i j v} \\
r_{i j v} F_{i j v} & =(1-\beta) \frac{1-\alpha}{\alpha} \Pi_{i j v}
\end{aligned}
$$

Thus, any results related to profits will apply to input expenditures as long as factor shares do not change.

Solving for the optimal labor and quantity of fertilizer from agrovet $j$ and location $v$, profits of 
$i$ from adopting at $j v$ are written as:

$$
\Pi_{i}=\theta_{i j v} \pi_{i} r_{i j v}^{-\sigma}
$$

where $\sigma \equiv \frac{1-\alpha}{\alpha}(1-\beta), \pi_{i}=p_{i}^{\frac{1}{\alpha}} w_{i}^{-\beta \frac{1-\alpha}{\alpha}} K_{i}$, and $\theta_{i b j v}=\kappa_{2} \widetilde{\theta}_{i b j v} \kappa_{10}^{30}$ Here, the profitability of fertilizer at this location is a function of the productivity shock, $\theta_{i j v}$, the (delivered) price of fertilizer itself, $r_{i j v}$, and profits based on local observables and technology $\pi_{i}$.

\section{B Distributions of Fertilizer Expenditures}

Above, we used the following property to generate a market clearing condition that can be taken to the data:

$$
\mathbb{E}\left[r F_{i} \mid \text { adopt at } j \text { in } v\right]=\mathbb{E}\left[r F_{i} \mid \text { adopt }\right]
$$

That is, that the expected fertilizer expenditures, conditional on adopting at location $j$, is the same as the expected fertilizer expenditure, conditional on adopting anywhere. This is a similar result to Eaton and Kortum (2003), where the price distribution conditional on being the lowest price supplier is the same as the unconditional price distribution at that destination. Here, we prove the similar result in the input adoption context.

In the model, fertilizer expenditures at a particular agrovet are a scalar function of ex-post profits when choosing that agrovet. Thus, we focus all proofs on the distribution of profits, and then the analogue to revenues and input expenditures follows directly. To begin, we first derive the distribution of profits for farmer $i$ who buys from agrovet $j$ in location $v$.

$$
\begin{aligned}
\operatorname{Pr}\left(\Pi_{i j v}>\pi\right) & =\operatorname{Pr}\left(\theta_{i j v} \pi_{i} r_{i j v}^{-\sigma}>\pi\right) \\
& =\operatorname{Pr}\left(\theta_{i j v}>\frac{\pi}{\pi_{i}} r_{i j v}^{\sigma}\right) \\
& =1-\exp \left(-T_{j v} \pi_{i}^{\varepsilon} r_{i j v}^{\varepsilon \sigma} \pi^{-\varepsilon}\right)
\end{aligned}
$$

Defining $\gamma_{i j v} \equiv \pi_{i}^{\varepsilon} r_{i j v}^{\varepsilon \sigma}$

$$
\operatorname{Pr}\left(\Pi_{i j v}>\pi\right)=1-\exp \left(-T_{j v} \gamma_{i j v} \pi^{-\varepsilon}\right)
$$

Similarly, the distribution of profits of the outside option of not purchasing fertilizer are written as:

$$
\operatorname{Pr}\left(\Pi_{i 0}>\pi\right)=1-\exp \left(-\Phi_{i 0} \pi^{-\varepsilon}\right)
$$

where $\Phi_{i 0}=T_{i 0} \gamma_{i 0} \equiv \pi_{i}^{\varepsilon}$

Next, defining $\Pi_{i}^{\max }$ as the profits available from the best agrovet option for farmer $i$, we write

\footnotetext{
${ }^{30} \kappa_{1}$ and $\kappa_{2}$ are constant functions of model parameters
} 
the distribution of these profits as:

$$
\begin{aligned}
\operatorname{Pr}\left(\Pi_{i}^{\max }>\pi\right) & =\operatorname{Pr}\left(\Pi_{i j v}>\pi \text { for any } j v\right) \\
& =1-\operatorname{Pr}\left(\Pi_{i j v}<\pi \forall j v\right)
\end{aligned}
$$

Since $\theta$ 's at each $j, v$ pair are drawn from independent distributions, this probability is simplified as:

$$
\begin{aligned}
\operatorname{Pr}\left(\Pi_{i}^{\max }>\pi\right) & =1-\operatorname{Pr}\left(\Pi_{i j v}<\pi \forall j v\right) \\
& =1-\prod_{v^{\prime} \in \mathcal{V}} \prod_{j \in \mathcal{J}_{v}} \operatorname{Pr}\left(\Pi_{i j v}<\pi\right) \\
& =1-\prod_{v^{\prime} \in \mathcal{V}} \prod_{j \in \mathcal{J}_{v}} \exp \left(-\pi^{-\varepsilon}\right)
\end{aligned}
$$

Defining $\Phi_{i}=\sum_{v^{\prime} \in \mathcal{V}_{j} \in \mathcal{J}_{v}} T_{j v} \gamma_{i j v}, \operatorname{Pr}\left(\Pi_{i}^{\max }>\pi\right)$ can be simplified to:

$$
\operatorname{Pr}\left(\Pi_{i}^{\max }>\pi\right)=1-\exp \left(-\Phi_{i} \pi^{-\varepsilon}\right)
$$

Thus, the CDF of max profits for village $i$ is written as:

$$
G_{i}^{\max }(\pi)=\operatorname{Pr}\left(\Pi_{i}^{\max }<\pi\right)=\exp \left(-\Phi_{i} \pi^{-\varepsilon}\right)
$$

with pdf:

$$
g_{i}^{\max }(\pi)=\varepsilon \Phi_{i} \pi^{-\varepsilon-1} \exp \left(-\Phi_{i} \pi^{-\varepsilon}\right)
$$

Similarly, adding the option of not adopting, the distribution of profits considering all options, $\Pi_{i}$, is written as:

$$
\begin{aligned}
\operatorname{Pr}\left(\Pi_{i}>\pi\right) & =\operatorname{Pr}\left(\Pi_{i j v}>\pi \text { for any } j v \cup \Pi_{i 0}>\pi\right) \\
& =1-\operatorname{Pr}\left(\Pi_{i j v}<\pi \forall j v \cap \Pi_{i 0}<\pi\right)
\end{aligned}
$$

Since $\theta$ 's at each $j, v$ pair and for not adopting are drawn from independent distributions, this probability is simplified as:

$$
\begin{aligned}
\operatorname{Pr}\left(\Pi_{i}>\pi\right) & =1-\operatorname{Pr}\left(\Pi_{i j v}<\pi \forall j v \cap \Pi_{i 0}<\pi\right) \\
& =1-\operatorname{Pr}\left(\Pi_{i 0}<\pi\right) \prod_{v^{\prime} \in \mathcal{V}} \prod_{j \in \mathcal{J}_{v}} \operatorname{Pr}\left(\Pi_{i j v}<\pi\right) \\
& =1-\exp \left(-T_{i 0} \gamma_{i 0} \pi^{-\varepsilon}\right) \prod_{v^{\prime} \in \mathcal{V}} \prod_{j \in \mathcal{J}_{v}} \exp \left(-T_{j v} \gamma_{i j v} \pi^{-\varepsilon}\right)
\end{aligned}
$$


Using the definitions for $\Phi_{i 0}$ and $\Phi_{i}$, this is simplified as:

$$
\operatorname{Pr}\left(\Pi_{i}>\pi\right)=1-\exp \left(-\left(\Phi_{i 0}+\Phi_{i}\right) \pi^{-\varepsilon}\right)
$$

Thus, the CDF of max profits for village $i$ is:

$$
G_{i}(\pi)=\exp \left(-\left(\Phi_{i 0}+\Phi_{i}\right) \pi^{-\varepsilon}\right)
$$

with pdf:

$$
g_{i}(\pi)=\varepsilon\left(\Phi_{i 0}+\Phi_{i}\right) \pi^{-\varepsilon-1} \exp \left(-\left(\Phi_{i 0}+\Phi_{i}\right) \pi^{-\varepsilon}\right)
$$

\section{Profits conditional on adoption}

Using this pdf, we now derive the CDF of agrovet profits, conditional on adoption. To do this, we start from the conditional probability formula:

$$
\operatorname{Pr}\left(\Pi_{i}^{\max }<\pi \mid \text { adopt }\right)=\frac{\operatorname{Pr}\left(\Pi_{i}^{\max }<\pi \cap \Pi_{i}^{\max }>\Pi_{i 0}\right)}{\operatorname{Pr}\left(\Pi_{i}^{\text {max }}>\Pi_{i 0}\right)}
$$

This can be re-written as:

$$
\begin{aligned}
\operatorname{Pr}\left(\Pi_{i}^{\text {max }}<\pi \mid \text { adopt }\right) & =\frac{1}{\operatorname{Pr}\left(\Pi_{i}^{\text {max }}>\Pi_{i 0}\right)} \int_{0}^{\pi} \operatorname{Pr}\left(s>\Pi_{i 0}\right) g_{i}^{\text {max }}(s) d s \\
& =\frac{1}{\operatorname{Pr}\left(\Pi_{i}^{\text {max }}>\Pi_{i 0}\right)} \int_{0}^{\pi} \exp \left(-\Phi_{i 0} s^{-\varepsilon}\right) \varepsilon \Phi_{i} s^{-\varepsilon-1} \exp \left(-\Phi_{i} s^{-\varepsilon}\right) d s \\
& =\frac{1}{\operatorname{Pr}\left(\Pi_{i}^{\text {max }}>\Pi_{i 0}\right)} \int_{0}^{\pi} \varepsilon \Phi_{i} s^{-\varepsilon-1} \exp \left(-\left(\Phi_{i 0}+\Phi_{i}\right) s^{-\varepsilon}\right) d s
\end{aligned}
$$

Mulitplying by $\frac{\Phi_{i 0}+\Phi_{i}}{\Phi_{i 0}+\Phi_{i}}$, and then factoring out $\frac{\Phi_{i}}{\Phi_{i 0}+\Phi_{i}}$, we have:

$\operatorname{Pr}\left(\Pi_{i}^{\text {max }}<\pi \mid\right.$ adopt $)=\frac{1}{\operatorname{Pr}\left(\Pi_{i}^{\text {max }}>\Pi_{i 0}\right)} \frac{\Phi_{i}}{\Phi_{i 0}+\Phi_{i}} \int_{0}^{\pi} \varepsilon\left(\Phi_{i 0}+\Phi_{i}\right) s^{-\varepsilon-1} \exp \left(-\left(\Phi_{i 0}+\Phi_{i}\right) s^{-\varepsilon}\right) d s$

From standard derivations using Fréchet, $\operatorname{Pr}\left(\Pi_{i}^{\max }>\Pi_{i 0}\right)=\frac{\Phi_{i}}{\Phi_{i 0}+\Phi_{i}}$, and thus:

$$
\begin{aligned}
\operatorname{Pr}\left(\Pi_{i}^{\text {max }}<\pi \mid \text { adopt }\right) & =\int_{0}^{\pi} \varepsilon\left(\Phi_{i 0}+\Phi_{i}\right) s^{-\varepsilon-1} \exp \left(-\left(\Phi_{i 0}+\Phi_{i}\right) s^{-\varepsilon}\right) d s \\
& =\operatorname{Pr}\left(\Pi_{i}<\pi\right)
\end{aligned}
$$

\section{Profits conditional on adoption from $j$}

Next, we derive the expected profits, conditional on adopting fertilizer from location $j$. Precisely, we will derive: 


$$
\operatorname{Pr}\left(\Pi_{i j v}<\pi \mid \text { adopt from jin } v\right)=\frac{\operatorname{Pr}\left(\Pi_{i j l}<\pi \cap \Pi_{i j v}>\Pi_{i j^{\prime} l} \forall\left(j^{\prime}, l\right) \cap \Pi_{i j v}>\Pi_{i 0}\right)}{\operatorname{Pr}\left(\Pi_{i j v}>\Pi_{i j^{\prime} l} \forall\left(j^{\prime}, l\right) \cap \Pi_{i j v}>\Pi_{i 0}\right)}
$$

The denominator in this equation is simply $\lambda_{i j v}$, and thus, we factor it out of the probability. The numerator is written similar to the previous derivation, where

$$
\operatorname{Pr}\left(\Pi_{i j v}<\pi \mid \text { adopt from jinv }\right)=\frac{1}{\lambda_{i j v}} \int_{0}^{\pi} \operatorname{Pr}\left(s>\Pi_{i j^{\prime} l} \forall\left(j^{\prime}, l\right) \cap s>\Pi_{i 0}\right) g_{i j v}(s) d s
$$

Defining $\widetilde{\Phi}_{i j v}=\left(\sum_{v^{\prime} \in \mathcal{V}} \sum_{j \in \mathcal{J}_{v}} T_{j v} \gamma_{i j v}\right)-T_{j v} \gamma_{i j v}$, we can simplify $\operatorname{Pr}\left(s>\Pi_{i j^{\prime} l} \forall\left(j^{\prime}, l\right) \cap s>\Pi_{i 0}\right)$ as

$$
\begin{aligned}
\operatorname{Pr}\left(s>\Pi_{i j^{\prime} l} \forall\left(j^{\prime}, l\right) \cap s>\Pi_{i 0}\right) & =\exp \left(-\Phi_{i 0} s^{-\varepsilon}\right) \exp \left(-\widetilde{\Phi}_{i j v} s^{-\varepsilon}\right) \\
& =\exp \left(-\left(\Phi_{i 0}+\widetilde{\Phi}_{i j v}\right) s^{-\varepsilon}\right)
\end{aligned}
$$

Thus, $\operatorname{Pr}\left(\Pi_{i j v}<\pi \mid\right.$ adopt from $\left.j\right)$ is written as:

$\operatorname{Pr}\left(\Pi_{i j v}<\pi \mid\right.$ adopt from $\left.j\right)=\frac{1}{\lambda_{i j v}} \int_{0}^{\pi} \exp \left(-\left(\Phi_{i 0}+\widetilde{\Phi}_{i j v}\right) s^{-\varepsilon}\right) \varepsilon T_{j v} \gamma_{i j v} \pi^{-\varepsilon-1} \exp \left(-T_{j v} \gamma_{i j v} s^{-\varepsilon}\right) d s$

Factoring out $\frac{T_{j v} \gamma_{i j v}}{\Phi_{i 0}+\Phi_{i}}$, and then noting that $\Phi_{i 0}+\Phi_{i}=\Phi_{i 0}+\widetilde{\Phi}_{i j v}+T_{j v} \gamma_{i j v}$, we have:

$$
\operatorname{Pr}\left(\Pi_{i j v}<\pi \mid \text { adopt from } j\right)=\frac{1}{\lambda_{i j v}} \frac{T_{j v} \gamma_{i j v}}{\Phi_{i 0}+\Phi_{i}} \int_{0}^{\pi} \varepsilon\left(\Phi_{i 0}+\Phi_{i}\right) \pi^{-\varepsilon-1} \exp \left(-\left(\Phi_{i 0}+\Phi_{i}\right) s^{-\varepsilon}\right) d s
$$

Since $\lambda_{i j v}=\frac{T_{j v} \gamma_{i j v}}{\Phi_{i 0}+\Phi_{i}}$, we land at the final result:

$$
\begin{aligned}
\operatorname{Pr}\left(\Pi_{i j v}<\pi \mid \text { adopt from } j\right) & =\int_{0}^{\pi} \varepsilon\left(\Phi_{i 0}+\Phi_{i}\right) \pi^{-\varepsilon-1} \exp \left(-\left(\Phi_{i 0}+\Phi_{i}\right) s^{-\varepsilon}\right) d s \\
& =\operatorname{Pr}\left(\Pi_{i}<\pi\right)
\end{aligned}
$$

Thus, the distribution of profits adopting from $j$ is the same as the distribution of profits adopting anywhere.

\section{Production Function Estimation with and without Fertilizer}

As our dataset is not equipped for panel production function estimation, we will be using the Tanzanian LSMS, which records output and input use by household-plot-time, and we exposit the estimation accordingly. That is, the production functions under different technologies should now be understood to be specific to a particular plot within a household. Simply manipulating the Cobb-Douglas production functions for plot $p$ of household $i$ in time $t$, we get the following 
representation for output per unit of land:

$$
\begin{aligned}
\log \left(\frac{Y_{i p t}}{K_{i p t}}\right) & =\left(1-\alpha_{0}\right) \log \left(\frac{L_{i p t}}{K_{i}}\right) \\
\log \left(\frac{Y_{i p t}}{K_{i p t}}\right) & =(1-\alpha) \beta \log \left(\frac{L_{i p t}}{K_{i p t}}\right)+(1-\alpha)(1-\beta) \log \left(\frac{M_{i p t}}{K_{i p t}}\right)
\end{aligned}
$$

To combine these equations into one specification, we need to eliminate $\log \left(\frac{M_{i p t}}{K_{i p t}}\right)$, which is not defined when fertilizer is not purchased. However, exploiting the fact that relative demand for fertilizer and labor is a constant function of local wages, delivered fertilizer prices and parameters, we can write:

$$
\begin{aligned}
\log \left(\frac{Y_{i p t}}{K_{i p t}}\right) & =\left(1-\alpha_{0}\right) \log \left(\frac{L_{i p t}}{K_{i}}\right) \\
\log \left(\frac{Y_{i p t}}{K_{i p t}}\right) & =(1-\alpha) \beta \log \left(\frac{L_{i p t}}{K_{i p t}}\right)+d_{i t}
\end{aligned}
$$

where $d_{i t}$ is a dummy variable for household $i$, and year $t$ (that is meant to absorb local wages and prices when using fertilizer). This motivates the following specification to test for differences in production parameters with and without fertilizer.

$$
\log \left(\frac{Y_{i p t}}{K_{i p t}}\right)=\left(1-\alpha_{0}\right) \log \left(\frac{L_{i p t}}{K_{i p t}}\right)+\left(\alpha_{0}-\alpha\right) \log \left(\frac{L_{i p t}}{K_{i p t}}\right) \cdot \mathbf{I}\left(M_{i p t}>0\right)+D F T_{i p t}+\text { Plot }_{i p}+u_{i p t}
$$

Here, $D F T_{i p t}$ is a district-time variable, with and without fertilizer use, meant to absorb differences is local wages and prices, and other local and shocks, that may vary by time and whether fertilizer is used. While one could argue that local wages and prices should vary at a more granular level, this is about as far as we can push the data given the other sets of fixed effects that are utilized. Plot $_{i p}$ is a fixed effect to absorb plot-specific sources of productivity differences. Within these fixed effects, we estimate $\alpha_{0}$ and $\alpha$ using labor per unit of land and an interaction with a dummy variable identifying fertilizer use. Appendix Table A7 reports these estimates. In the preferred specification, we find that $\alpha_{0}=0.57$ and $\alpha=0.421$.

The last production parameter to estimate is the expenditure share of labor compared relative to total expenditures on labor and fertlizer. For this measure, we also use the Tanzanian LSMS. We first average district-level, activity specific wages from all plots that hire labor, and then construct an implied labor cost on each plot by summing the product of labor hours on each activity and the average wage for that activity. Then, for those who adopt fertilizer, we divide the value of fertilizer used on that plot by the sum of this same value and implied labor expenditure. For the whole of Tanzania, the average of this fertilizer expenditure share is 0.25 , and we use this value for our counterfactuals by imposing that $\beta=0.75$. Of note, the mean and median values of fertilizer expenditure share for the subsample of regions in norther Tanzania (Arusha, Kilimanjaro, Manyara, Tanga) is slightly higher at 0.28 . 


\section{Mark-ups}

From above, we can write the expected fertilizer revenues for agrovet $j$ in location $v$ as:

$$
\mathbb{E}\left[v_{j v}\right]=\sum_{i} \mu_{i} \lambda_{i j v \mid a d o p t} \mathbb{E}\left[F_{i} \mid \text { adopt at } j v\right]
$$

Since fertilizer expenditures are proportional to profits, and profits are invariant to the choice that is made (in expectation)we have:

$$
\mathbb{E}\left[v_{j v}\right]=(1-\beta) \frac{1-\alpha}{\alpha} \sum_{i} \lambda_{i j v} \mathbb{E}\left[\Pi_{i}\right]
$$

Differentiating with respect to the fertilizer price, $r_{j v}$, the elasticity of expected revenues with respect to own price is:

$$
\frac{d \mathbb{E}\left[v_{j v}\right]}{d r_{j v}} \frac{r_{j v}}{\mathbb{E}\left[v_{j v}\right]}=\sum s_{i j v}\left(\frac{d \lambda_{i j v}}{d r_{j v}} \frac{r_{j v}}{\lambda_{i j v}}+\frac{d \mathbb{E}\left[\Pi_{i}\right]}{d r_{j v}} \frac{r_{j v}}{\mathbb{E}\left[\Pi_{i}\right]}\right)
$$

where $s_{i j v}=\frac{\lambda_{i j v \mid a d o p t} \mathbb{E}\left[r m_{i}\right]}{\sum_{i^{\prime}} \lambda_{i^{\prime} j v \mid a d o p t} \mathbb{E}\left[r m_{i^{\prime}}\right]}$. As a function of model parameters, $\frac{d \lambda_{i j v}}{d r_{j v}} \frac{r_{j v}}{\lambda_{i j v}}$ is written as:

$$
\frac{d \lambda_{i j v}}{d r_{j v}} \frac{r_{j v}}{\lambda_{i j v}}=-\varepsilon_{a}\left(1-\lambda_{i j v}\right)
$$

Given the assumption of the Frechet distribution, $\mathbb{E}\left[\Pi_{i}\right]$ can be written as:

$$
\mathbb{E}\left[\Pi_{i}\right]=\kappa\left(\Phi_{i 0}+\Phi_{i}\right)^{\frac{1}{\varepsilon}}
$$

where $\kappa$ is a function of distribution parameters. Log-differentiating, it is straightforward to show that:

$$
\frac{d \mathbb{E}\left[\Pi_{i}\right]}{d r_{j v}} \frac{r_{j v}}{\mathbb{E}\left[\Pi_{i}\right]}=-\frac{\varepsilon_{a}}{\varepsilon} \lambda_{i j v}
$$

Thus, the elasticity of expected revenues to price can be written as:

$$
\frac{d \mathbb{E}\left[v_{j v}\right]}{d r_{j v}} \frac{r_{j v}}{\mathbb{E}\left[v_{j v}\right]}=-\varepsilon_{a} \sum_{i} s_{i j v}\left(\left(1-\lambda_{i j v}\right)+\frac{1}{\varepsilon} \lambda_{i j v}\right)
$$

Since $\sum_{i} s_{i j v}=1$ for each $j v$, the elasticity of expected revenues to price can be simplified as:

$$
\varepsilon_{v} \equiv \frac{d \mathbb{E}\left[v_{j v}\right]}{d r_{j v}} \frac{r_{j v}}{\mathbb{E}\left[v_{j v}\right]}=-\varepsilon_{a}+\frac{\varepsilon-1}{\varepsilon} \varepsilon_{a} \sum_{i} s_{i j v} \lambda_{i j v}
$$


Mean

Panel A. Travel costs to markets and major hub towns

Distance to nearest market center $(\mathrm{km})$ - Google maps

6.52

(9.94)

Time for round-trip journey to nearest market center - surveys

Cost of round-trip from village to nearest market center (USD) - surveys

Cost of round-trip from market center to village (paid by enumerator)

Distance to a major hub (km) - Google maps

171.5

Round-trip travel time to a major hub (mins) - Google maps

Round-trip cost of travel to a major hub (USD) - surveys

\section{Panel B. Road quality}

Field Measurement of roads from market centers to villages

Percent of road that is:

Paved

Dirt

0.42

Gravel

0.38

Travel speed on feeder roads and rural roads - $\mathrm{km} / \mathrm{hr}$ (GPS surveys) ${ }^{1}$

Google estimates

Travel speed on feeder roads and rural roads - $\mathrm{km} / \mathrm{hr}$ (Google)

Travel speed on major roads - $\mathrm{km} / \mathrm{hr}(\text { Google })^{2}$

46.1

(12.7)

Notes: The average village had approximately 480 households in the 2012 census and ranged in size from 48 to 3241. Table includes 1,168 villages in the Kilimanjaro and Manyara regions of Tanzania. There are 1,183 total villages in the area but several were not visited. Standard deviations in parentheses.

${ }^{1}$ Feeder roads and rural roads are routes from villages to a nearest market.

${ }^{2}$ Major roads are routes from markets to a nearest city. 


\begin{tabular}{|c|c|c|c|c|c|c|c|c|c|}
\hline & (1) & (2) & (3) & (4) & (5) & (6) & (7) & (8) & (9) \\
\hline & \multirow{2}{*}{\multicolumn{3}{|c|}{$\begin{array}{c}\text { From market center } \\
\text { to major hub town } \\
\text { (Transport Operator Surveys) }\end{array}$}} & \multicolumn{6}{|c|}{ From village center to market center } \\
\hline & & & & \multicolumn{3}{|c|}{ Enumerator's Trips } & \multicolumn{3}{|c|}{ Transport Operator Surveys } \\
\hline & Cost & Cost & Hours & Cost & Cost & Hours & Cost & Cost & Hours \\
\hline \multicolumn{10}{|l|}{ Panel A. Costs from Markets } \\
\hline Google maps: kilometers to destination & $\begin{array}{c}0.021 * * * \\
(0.000)\end{array}$ & & & & & & & & \\
\hline Google maps: hours to destination & & $\begin{array}{c}1.261 * * * \\
(0.028)\end{array}$ & $\begin{array}{c}0.998 * * * \\
(0.032)\end{array}$ & & & & & & \\
\hline Number of markets & 201 & 201 & 201 & & & & & & \\
\hline Number of observations & 900 & 900 & 893 & & & & & & \\
\hline \multicolumn{10}{|l|}{ Panel B. Costs from villages } \\
\hline Google maps: kilometers to destination & & & & $\begin{array}{c}0.117 * * * \\
(0.011)\end{array}$ & & & $\begin{array}{c}0.088 * * * \\
(0.009)\end{array}$ & & \\
\hline Google maps: hours to destination & & & & & $\begin{array}{c}3.544 * * * \\
(0.274)\end{array}$ & $\begin{array}{c}0.724 * * * \\
(0.069)\end{array}$ & & $\begin{array}{c}2.609 * * * \\
(0.252)\end{array}$ & $\begin{array}{c}0.839 * * * \\
(0.076)\end{array}$ \\
\hline Number of villages & & & & 1127 & 1033 & 1036 & 1133 & 1133 & 1027 \\
\hline Number of observations & & & & 1127 & 1033 & 1036 & 1133 & 1133 & 1027 \\
\hline $\begin{array}{l}\text { Notes: Data is constructed from intervie } \\
226 \text { market centers in our sample. In bot } \\
\text { Dar es Salaam); in Manyara, they were } \\
\text { hub level for Panel A, while it is the vill } \\
*, * * \text {, and *** indicate significance at } 10\end{array}$ & $\begin{array}{l}\text { NS with tran } \\
\text { h regions, tr } \\
\text { lso asked at } \\
\text { ge-market } \\
\%, 5 \% \text {, and }\end{array}$ & $\begin{array}{l}\text { sportation } \\
\text { ransportatio } \\
\text { bout } 3 \text { addi } \\
\text { pair level } \mathrm{f} \\
1 \% \text { respec }\end{array}$ & $\begin{array}{l}\text { operators, a } \\
\text { operators } \\
\text { tional hubs } \\
\text { or Panel B. } \\
\text { tively. }\end{array}$ & $\begin{array}{l}\text { Id from trav } \\
\text { were asked } \\
\text { Tanga, Dod } \\
\text { tandard err }\end{array}$ & $\begin{array}{l}\text { el costs and } \\
\text { about the } 3 \\
\text { oma, and } B \\
\text { ors in paren }\end{array}$ & $\begin{array}{l}\text { times inc } \\
\text { most impc } \\
\text { abati). The } \\
\text { theses (clu }\end{array}$ & $\begin{array}{l}\text { red by enur } \\
\text { ant hubs ( } \\
\text { nit of obse } \\
\text { ered by ma }\end{array}$ & $\begin{array}{l}\text { nerators. T1 } \\
\text { Moshi, Arus } \\
\text { rvation is t } \\
\text { rket in Pan }\end{array}$ & $\begin{array}{l}\text { here are } \\
\text { ha, and } \\
\text { he market- } \\
\text { el A). }\end{array}$ \\
\hline
\end{tabular}




\begin{tabular}{|c|c|c|}
\hline & $\begin{array}{c}(1) \\
\text { Mean }\end{array}$ & $\begin{array}{c}\text { (2) } \\
\text { Coefficient from regression on } \\
\text { standardized distance from regional } \\
\text { hubs }\end{array}$ \\
\hline \multicolumn{3}{|l|}{ Panel A. Demographic and background characteristics } \\
\hline Age & $\begin{array}{c}49.76 \\
(15.23)\end{array}$ & $\begin{array}{l}-0.98 * \\
(0.52)\end{array}$ \\
\hline Female & 0.45 & $\begin{array}{l}-0.02 \\
(0.02)\end{array}$ \\
\hline Married & 0.76 & $\begin{array}{c}0.00 \\
(0.01)\end{array}$ \\
\hline Household size & $\begin{array}{c}4.95 \\
(2.78)\end{array}$ & $\begin{array}{c}0.26 * * \\
(0.11)\end{array}$ \\
\hline Years of education & $\begin{array}{c}6.58 \\
(3.56)\end{array}$ & $\begin{array}{c}-0.31 * * * \\
(0.11)\end{array}$ \\
\hline Home has thatch roof & 0.17 & $\begin{array}{c}0.03 \\
(0.02)\end{array}$ \\
\hline Has cell phone & 0.89 & $\begin{array}{c}-0.03 * * * \\
(0.01)\end{array}$ \\
\hline Has bank account & 0.15 & $\begin{array}{c}-0.05 * * * \\
(0.01)\end{array}$ \\
\hline Has mobile money account & 0.77 & $\begin{array}{c}-0.08 * * * \\
(0.02)\end{array}$ \\
\hline Acres of land & $\begin{array}{c}5.46 \\
(13.89)\end{array}$ & $\begin{array}{c}1.37 * * \\
(0.57)\end{array}$ \\
\hline Has market business & 0.28 & $\begin{array}{c}-0.05 * * * \\
(0.01)\end{array}$ \\
\hline Annual total income from non-farming (USD) & $\begin{array}{c}408.9 \\
(772.60)\end{array}$ & $\begin{array}{c}-74.72 * * \\
(30.25)\end{array}$ \\
\hline \multicolumn{3}{|l|}{ Panel B. Production Capacity (in kg/acre) ${ }^{1}$} \\
\hline FAO-GAEZ production capacity for low input level & $\begin{array}{c}719.1 \\
(296.70)\end{array}$ & $\begin{array}{c}39.83 \\
(28.87)\end{array}$ \\
\hline FAO-GAEZ production capacity for high input level & $\begin{array}{c}3039 \\
(928.20)\end{array}$ & $\begin{array}{c}-282.91 * * * \\
(81.80)\end{array}$ \\
\hline FAO-GAEZ production difference between high and low & $\begin{array}{c}2320 \\
(779.50)\end{array}$ & $\begin{array}{c}-322.75 * * * \\
(67.22)\end{array}$ \\
\hline \multicolumn{3}{|l|}{ Panel C. Harvest Output } \\
\hline Total harvest output in 2016 long rains $(\mathrm{kg})$ & $\begin{array}{c}928.7 \\
(1360.00)\end{array}$ & $\begin{array}{l}-16.62 \\
(51.18)\end{array}$ \\
\hline Harvest output per acre & $\begin{array}{c}455.3 \\
(384.30)\end{array}$ & $\begin{array}{c}-85.11 * * * \\
(17.46)\end{array}$ \\
\hline $\begin{array}{l}\text { Value of harvest output at average } \\
\text { regional post-harvest price }\end{array}$ & $\begin{array}{c}201.9 \\
(295.60) \\
\end{array}$ & $\begin{array}{c}-3.61 \\
(11.13) \\
\end{array}$ \\
\hline
\end{tabular}




\begin{tabular}{|c|c|c|}
\hline & $\begin{array}{c}(1) \\
\text { Mean }\end{array}$ & $\begin{array}{c}\text { (2) } \\
\text { Coefficient from regression } \\
\text { on standardized distance from } \\
\text { regional hubs }\end{array}$ \\
\hline \multicolumn{3}{|c|}{ Panel A. Summary measures of access to input retailers } \\
\hline $\begin{array}{l}\text { Has at least } 1 \text { agrovet within } 10 \mathrm{~km} \text { of village } \\
\text { which sells fertilizer or seeds }\end{array}$ & 0.75 & $\begin{array}{c}-0.14 * * * \\
(0.01)\end{array}$ \\
\hline $\begin{array}{l}\text { Number of agrovets within } 10 \mathrm{~km} \text { of village } \\
\text { which sells fertilizer or seeds }\end{array}$ & $\begin{array}{c}7.79 \\
(8.96)\end{array}$ & $\begin{array}{l}-2.93 * * * \\
(0.25)\end{array}$ \\
\hline $\begin{array}{l}\text { Distance to nearest agrovet } \\
\text { which sells fertilizer or seeds }\end{array}$ & $\begin{array}{c}6.79 \\
(15.15)\end{array}$ & $\begin{array}{c}3.17 * * * \\
(0.47)\end{array}$ \\
\hline \multicolumn{3}{|c|}{ Panel B. Travel-cost adjusted prices faced by farmers } \\
\hline $\begin{array}{l}\text { Minimum travel-cost adjusted price } \\
\text { for } 50 \mathrm{~kg} \text { of Urea }{ }^{1}\end{array}$ & $\begin{array}{l}24.19 \\
(4.66)\end{array}$ & $\begin{array}{c}2.33 * * * \\
(0.12)\end{array}$ \\
\hline \multicolumn{3}{|c|}{ Decomposition of price between retail price and cost of transportation } \\
\hline $\begin{array}{l}\text { Retail price at the location with the lowest } \\
\text { travel-cost adjusted price (USD) }\end{array}$ & $\begin{array}{l}19.82 \\
(2.63)\end{array}$ & $\begin{array}{c}1.09 * * * \\
(0.07)\end{array}$ \\
\hline $\begin{array}{l}\text { Cost of travel to obtain minimum travel-cost } \\
\text { adjusted price (USD) }\end{array}$ & $\begin{array}{l}4.372 \\
(4.39) \\
\end{array}$ & $\begin{array}{c}1.24 * * * \\
(0.13)\end{array}$ \\
\hline \multicolumn{3}{|c|}{$\begin{array}{l}\text { Notes: The unit of observation is the village. Data is from the universe of villages in Kilimanjaro and Manyara regions (N } \\
=1,183 \text { ). Travel costs imputed from transport surveys and Google maps. In Column } 1 \text {, standard deviations are in } \\
\text { parentheses. In Column } 2 \text {, standard errors in parentheses. } \\
*, * * \text {, and } * * * \text { indicate significance at } 10 \%, 5 \% \text {, and } 1 \% \text {. } \\
{ }^{1} \text { We assume farmers buy a } 50 \mathrm{~kg} \text { bag in one trip (enough for } 1 \text { acre), and must incur the cost of a round-trip for herself, } \\
\text { plus the cost of carrying the bag of fertilizer, equivalent to } 0.7 \text { trips. }\end{array}$} \\
\hline
\end{tabular}




\section{Panel A. Summary measures of access to output markets}

Has at least 1 maize seller within $10 \mathrm{~km}$ of village

Number of maize sellers within $10 \mathrm{~km}$ of village

Distance to the nearest output market with maize sellers $(\mathrm{km})$

$\begin{array}{cc} & \text { from regional h } \\ 0.67 & -0.16^{* * *} * \\ & (0.01) \\ 1.89 & -1.06^{* * *} \\ (2.48) & (0.07) \\ 8.67 & 5.65 * * * \\ (14.17) & (0.42)\end{array}$

Panel B. Maximum imputed travel-cost adjusted price if farmers were to sell in a local market

Market survey: maximum travel-cost adjusted price immediately after 2017 harvest (USD)
9.05

(7.06)
$-3.08 * * *$

Decomposition of price between retail price and cost of transportation

Retail price at the location with the highest travel-cost adjusted price (USD)

Cost of travel to obtain the highest travel-cost adjusted price (USD)
$0.80 * * *$

Panel B2. Price available within village by maize-buying intermediaries immediately after last season's harvest Farmer surveys: average "going price" in local 30.38 0.16 village immediately after previous harvest ${ }^{2}$

Farmer surveys: average village sales price after previous harvest ${ }^{2}$

Notes: The unit of observation is the village. Data is from the universe of villages in Kilimanjaro and Manyara regions $(\mathrm{N}=1,183)$. Travel costs imputed from transport surveys and Google maps. In Column 1, standard deviations are in parentheses. In Column 2, standard errors in parentheses.

$*$, **, and $* * *$ indicate significance at $10 \%, 5 \%$, and $1 \%$.

${ }^{1}$ We assume farmers sell a $120 \mathrm{~kg}$ maize bag in one trip, and must incur the cost of a round trip for herself and the cost of carrying the maize that is equivaent to 1.7 trips.

${ }^{2}$ Data is only available from the farmer surveys (2,171 farmers in 137 villages). 


\begin{tabular}{|c|c|c|c|}
\hline & (1) & $(2)$ & (3) \\
\hline & \multirow{2}{*}{ Mean } & \multicolumn{2}{|c|}{$\begin{array}{c}\text { Coefficient from regression on standardizec } \\
\text { distance from regional hubs }\end{array}$} \\
\hline & & No controls & $\begin{array}{l}\text { Controls for soil and } \\
\text { farmer characteristics }\end{array}$ \\
\hline \multicolumn{4}{|l|}{ Panel A: Input usage } \\
\hline Used chemical fertilizer in previous long rains & 0.39 & $\begin{array}{c}-0.17 * * * \\
(0.03)\end{array}$ & $\begin{array}{c}-0.09 * * * \\
(0.03)\end{array}$ \\
\hline Quantity of chemical fertilizer used $(\mathrm{kg})$ & $\begin{array}{c}19.84 \\
(31.63)\end{array}$ & $\begin{array}{c}-13.06 * * * \\
(2.15)\end{array}$ & $\begin{array}{c}-6.46 * * * \\
(1.74)\end{array}$ \\
\hline Used improved seeds in previous long rains & 0.66 & $\begin{array}{c}-0.07 * * * \\
(0.02)\end{array}$ & $\begin{array}{c}-0.05 * * \\
(0.02)\end{array}$ \\
\hline Quantity of improved seeds used (kg) & $\begin{array}{c}6.29 \\
(8.21)\end{array}$ & $\begin{array}{c}-1.30 * * * \\
(0.36)\end{array}$ & $\begin{array}{c}-1.21 * * * \\
(0.44)\end{array}$ \\
\hline \multicolumn{4}{|l|}{ Panel B. Maize sales } \\
\hline Sold maize after previous long rains & 0.32 & $\begin{array}{c}-0.09 * * * \\
(0.02)\end{array}$ & $\begin{array}{c}-0.06 * * \\
(0.03)\end{array}$ \\
\hline Total quantity sold (kg) & $\begin{array}{c}388.1 \\
(1142.00)\end{array}$ & $\begin{array}{c}-97.86 * * * \\
(35.11)\end{array}$ & $\begin{array}{c}-112.16^{* *} \\
(48.86)\end{array}$ \\
\hline \multicolumn{4}{|l|}{ Sales to agents at home } \\
\hline Agent visited homestead & 0.31 & $\begin{array}{c}-0.14 * * * \\
(0.03)\end{array}$ & $\begin{array}{c}-0.09 * * * \\
(0.03)\end{array}$ \\
\hline Sold maize to an agent after previous long rains & 0.17 & $\begin{array}{c}-0.07 * * * \\
(0.02)\end{array}$ & $\begin{array}{c}-0.04 * * \\
(0.02)\end{array}$ \\
\hline Quantity sold to agents (kg) & $\begin{array}{c}142 \\
(433.70)\end{array}$ & $\begin{array}{c}-46.39 * * * \\
(13.80)\end{array}$ & $\begin{array}{c}-39.11 * * \\
(18.61)\end{array}$ \\
\hline \multicolumn{4}{|l|}{ Sales at market } \\
\hline Sold maize at a market after previous long rains & 0.06 & $\begin{array}{c}-0.03 * * * \\
(0.01)\end{array}$ & $\begin{array}{c}-0.03 * * * \\
(0.01)\end{array}$ \\
\hline Quantity sold at market $(\mathrm{kg})$ & 34.42 & $-14.61 * * *$ & $-15.26^{* *}$ \\
\hline Panel C. Maize purchases & $(197.10)$ & $(5.32)$ & $(7.72)$ \\
\hline Farmer ever buys maize & 0.48 & $\begin{array}{c}0.11 * * * \\
(0.02)\end{array}$ & $\begin{array}{c}0.08 * * * \\
(0.02)\end{array}$ \\
\hline Quantity purchased in typical year (kg) & $\begin{array}{c}152.3 \\
(315.50)\end{array}$ & $\begin{array}{c}75.67 * * * \\
(15.79)\end{array}$ & $\begin{array}{c}65.05 * * * \\
(17.92)\end{array}$ \\
\hline \multicolumn{4}{|l|}{ Net buying } \\
\hline Farmer buys maize but sells none & 0.37 & $\begin{array}{c}0.11 * * * \\
(0.02)\end{array}$ & $\begin{array}{c}0.08 * * * \\
(0.03)\end{array}$ \\
\hline Farmer sells maize and buys none & 0.24 & $\begin{array}{c}-0.09 * * * \\
(0.02)\end{array}$ & $\begin{array}{c}-0.06 * * * \\
(0.02)\end{array}$ \\
\hline Farmer buys and sells maize & 0.08 & $\begin{array}{l}-0.00 \\
(0.01)\end{array}$ & $\begin{array}{c}0.00 \\
(0.01)\end{array}$ \\
\hline Net buyer (quantity bought $>$ quantity sold) & 0.44 & $\begin{array}{c}0.10 * * * \\
(0.02)\end{array}$ & $\begin{array}{c}0.07 * * \\
(0.03)\end{array}$ \\
\hline Net seller (quantity bought < quantity sold) & 0.26 & $\begin{array}{c}-0.08 * * * \\
(0.02)\end{array}$ & $\begin{array}{c}-0.06 * * \\
(0.03)\end{array}$ \\
\hline
\end{tabular}

Notes: $\mathrm{N}=2,845$ farmers in 246 villages. See text for sampling details. Standard deviations are in parentheses in Column 1. Standard errors, clustered at village level, in parentheses in Columns 2-3. $*$, **, and $* * *$ indicate significance at $10 \%, 5 \%$, and $1 \%$. 


\begin{tabular}{|c|c|c|}
\hline & (1) & (2) \\
\hline & \multicolumn{2}{|c|}{ Agrovet Chosen } \\
\hline Kilometers to agrovet & $\begin{array}{c}-0.171 * * * \\
(0.009)\end{array}$ & \\
\hline $\begin{array}{l}\text { Dummies for agrovet di } \\
\text { between }(0,5] \mathrm{km}\end{array}$ & & $\begin{array}{c}-1.380 * * * \\
(0.372)\end{array}$ \\
\hline between $(5,10] \mathrm{km}$ & & $\begin{array}{c}-2.914 * * * \\
(0.379)\end{array}$ \\
\hline between $(10,15] \mathrm{km}$ & & $\begin{array}{c}-4.331 * * * \\
(0.380)\end{array}$ \\
\hline between $(15,20] \mathrm{km}$ & & $\begin{array}{c}-5.367 * * * \\
(0.400)\end{array}$ \\
\hline between $(20,30] \mathrm{km}$ & & $\begin{array}{c}-5.875^{* * *} \\
(0.378)\end{array}$ \\
\hline between $(30,40] \mathrm{km}$ & & $\begin{array}{c}-7.602 * * * \\
(0.449)\end{array}$ \\
\hline between $(40,50] \mathrm{km}$ & & $\begin{array}{c}-8.685^{* * *} \\
(0.495)\end{array}$ \\
\hline between $(50,100] \mathrm{km}$ & & $\begin{array}{c}-10.625^{* * * *} \\
(0.560)\end{array}$ \\
\hline over $100 \mathrm{~km}$ & & $\begin{array}{c}-14.253 * * * \\
(0.992) \\
\end{array}$ \\
\hline
\end{tabular}

Notes: $\mathrm{N}=519$ farmers, 119 observed locations. Omitted group is agrovet located in respondent's village. Standard errors in parentheses. *, **, and *** indicate significance at $10 \%, 5 \%$, and $1 \%$. 


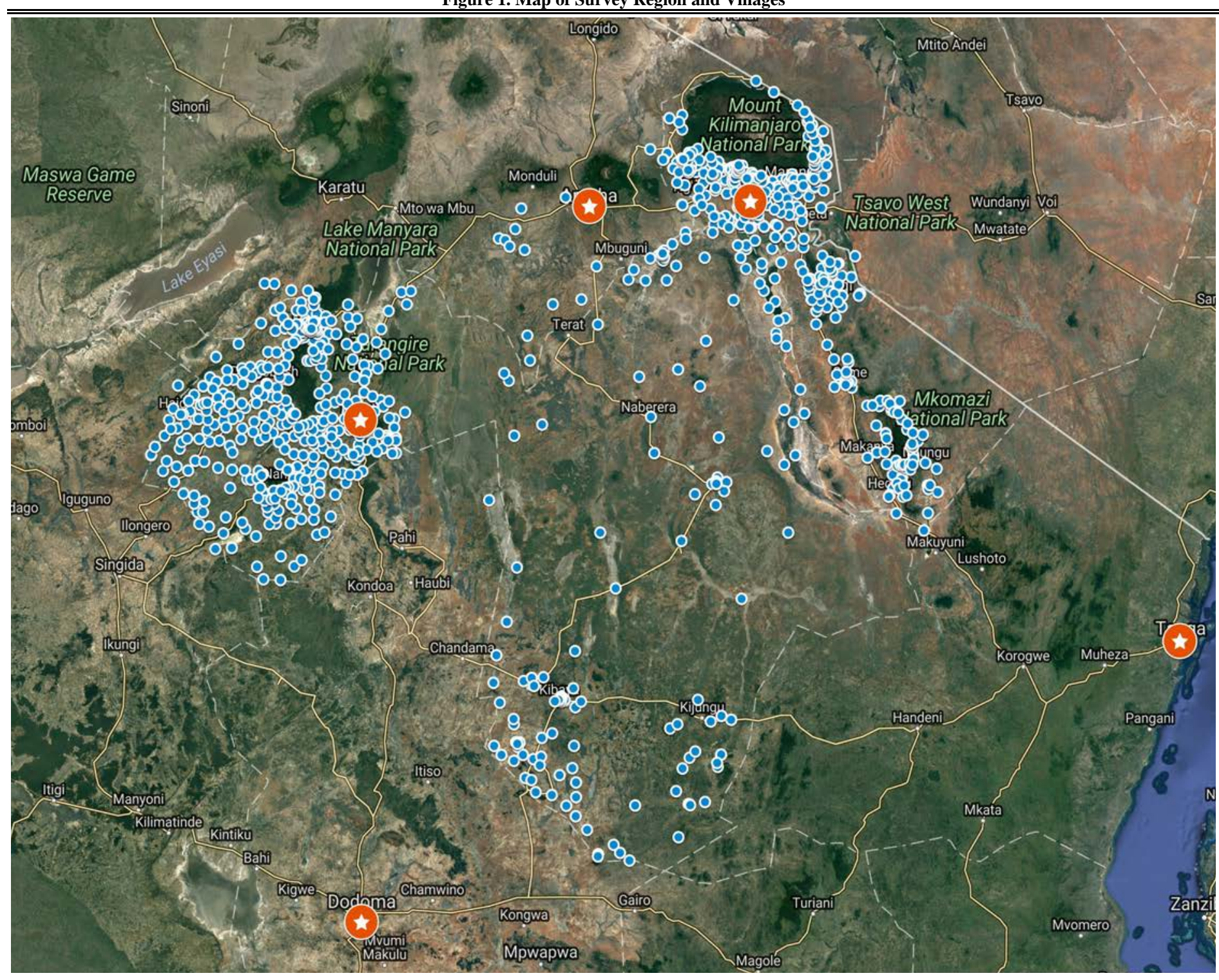


A. CDF of Maize Price

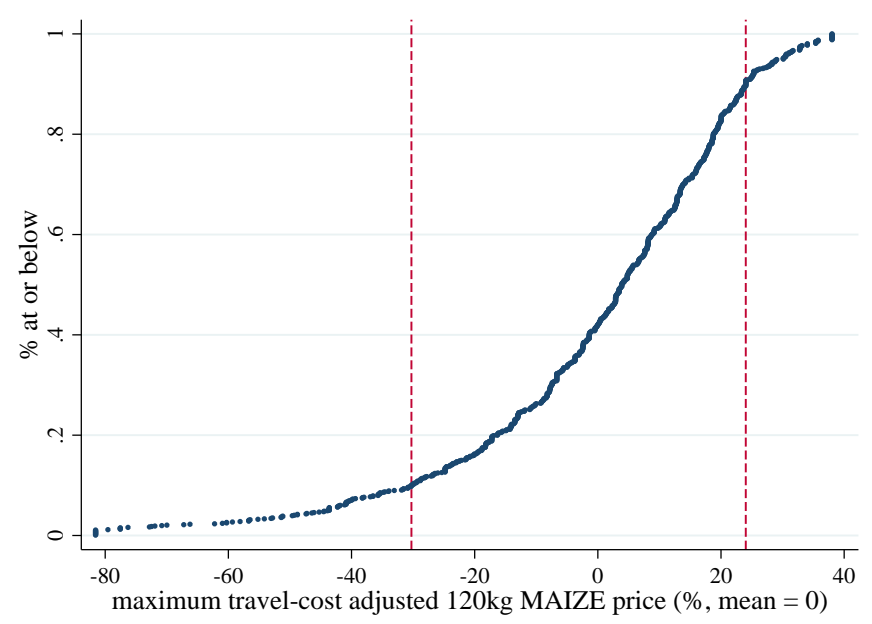

B. CDF of Fertilizer Price

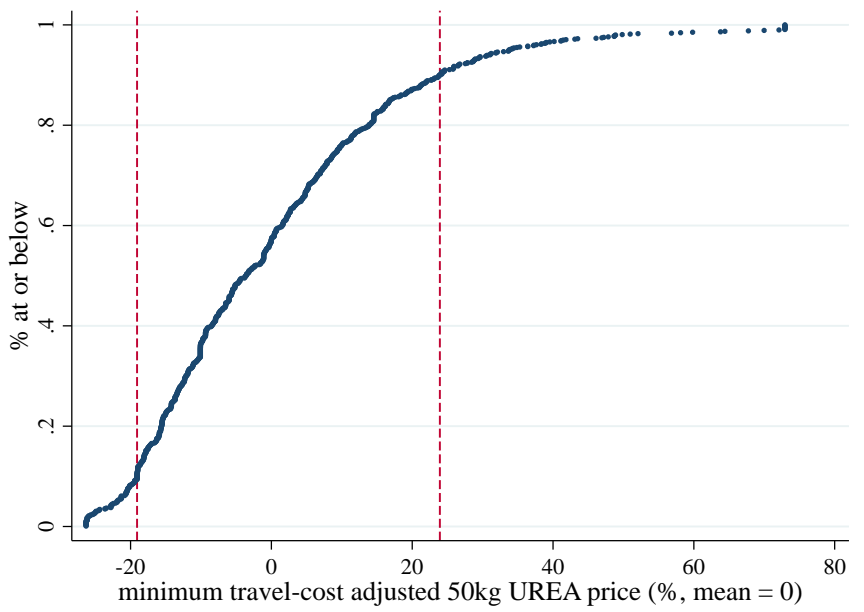

\section{CDF of Ratio of Maize Price to Fertilizer Price}

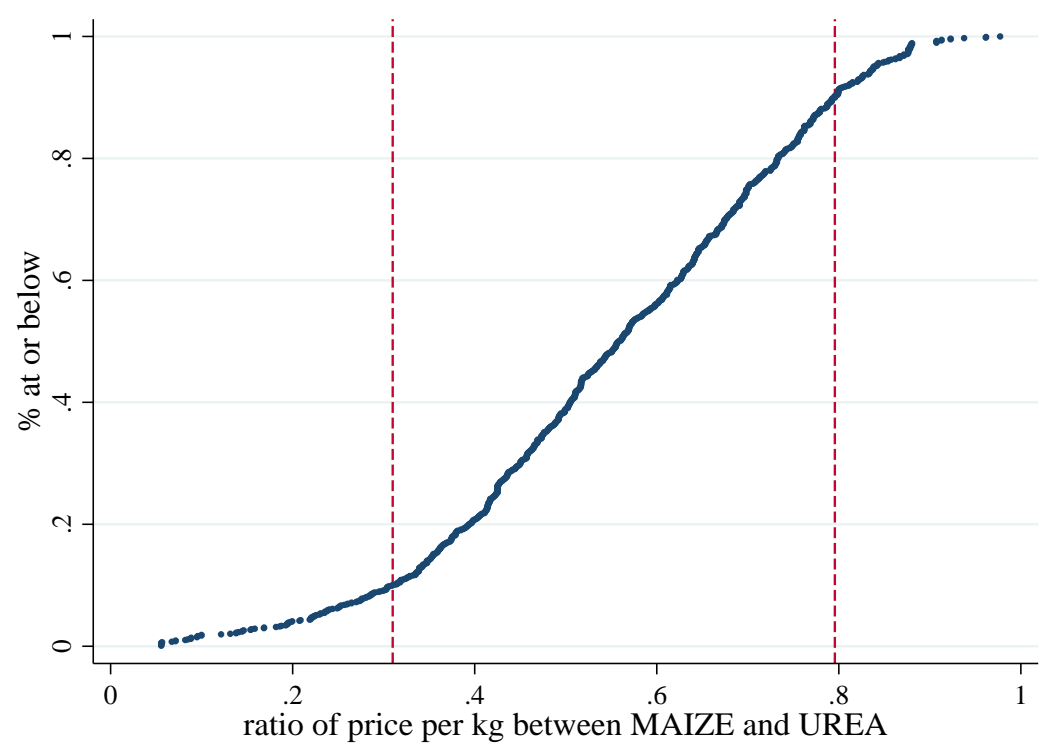

Notes: Each observation represents a village. Travel-cost adjusted prices are calculated through observed prices from an agrovet survey, a maize price survey at markets and transport cost information collected from interviews with transport operators.

Vertical dotted lines represent a 10 percentile and a 90 percentile of the distribution. 


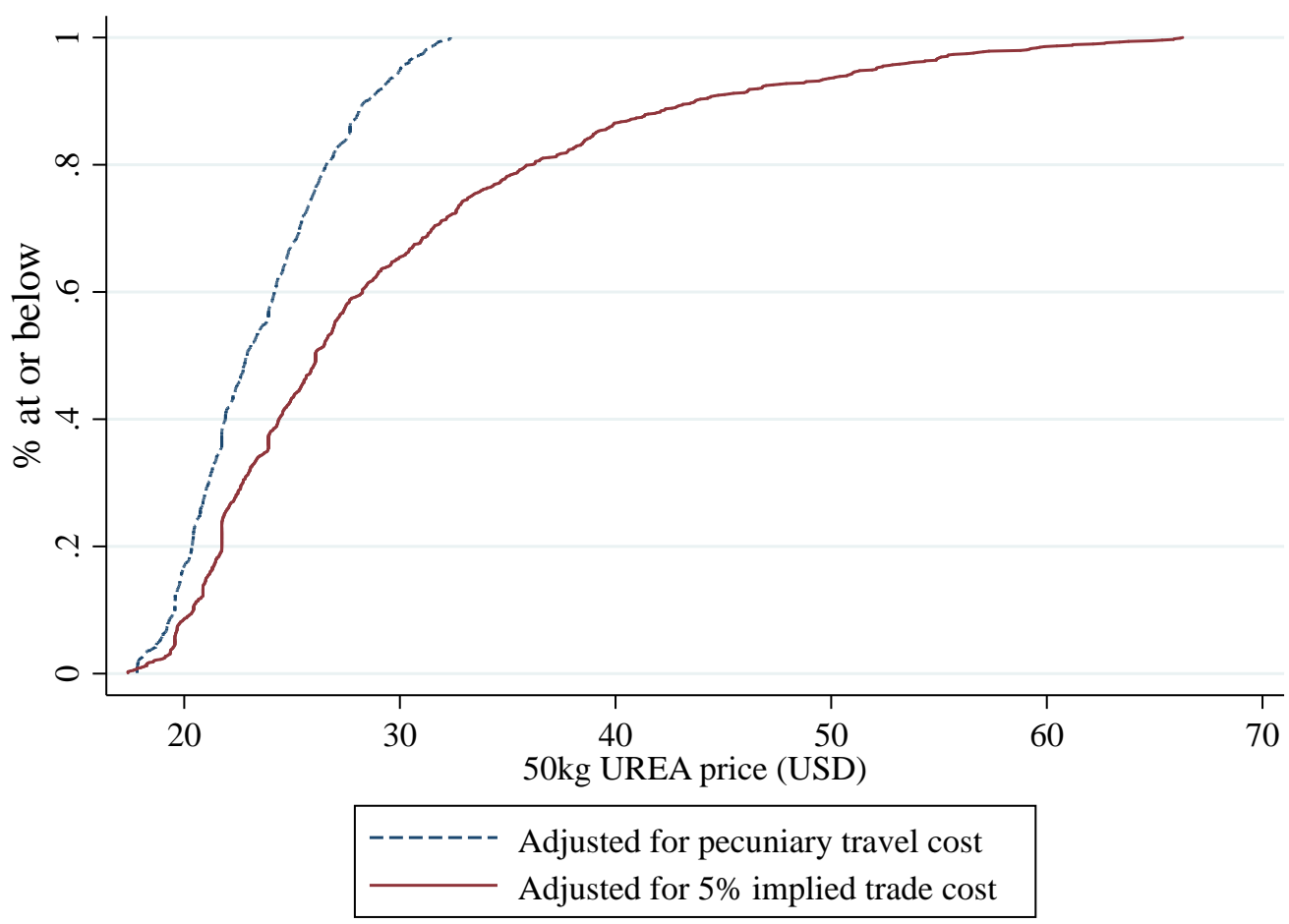

Notes: Each observation represents a village. Travel-cost adjusted prices are calculated through observed prices from an agrovet survey and transport cost information collected from interviews with transport operators. The CDFs are censored at a 95 percentile for a better visual comparison. 


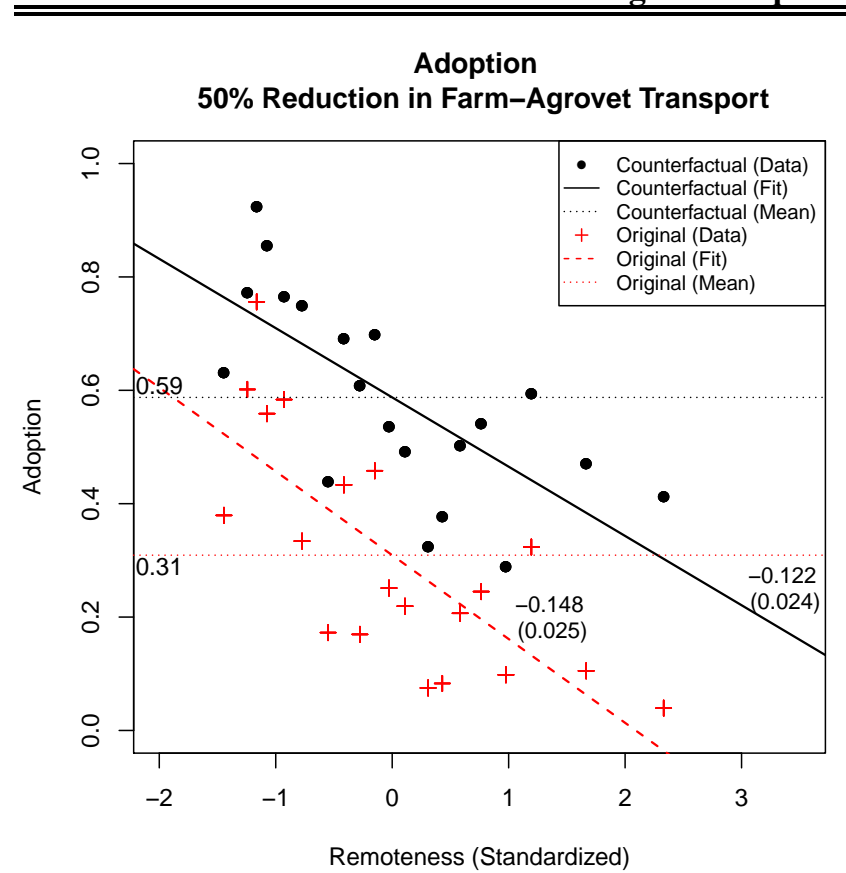

Fertilizer Expenditures 50\% Reduction in Farm-Agrovet Transport

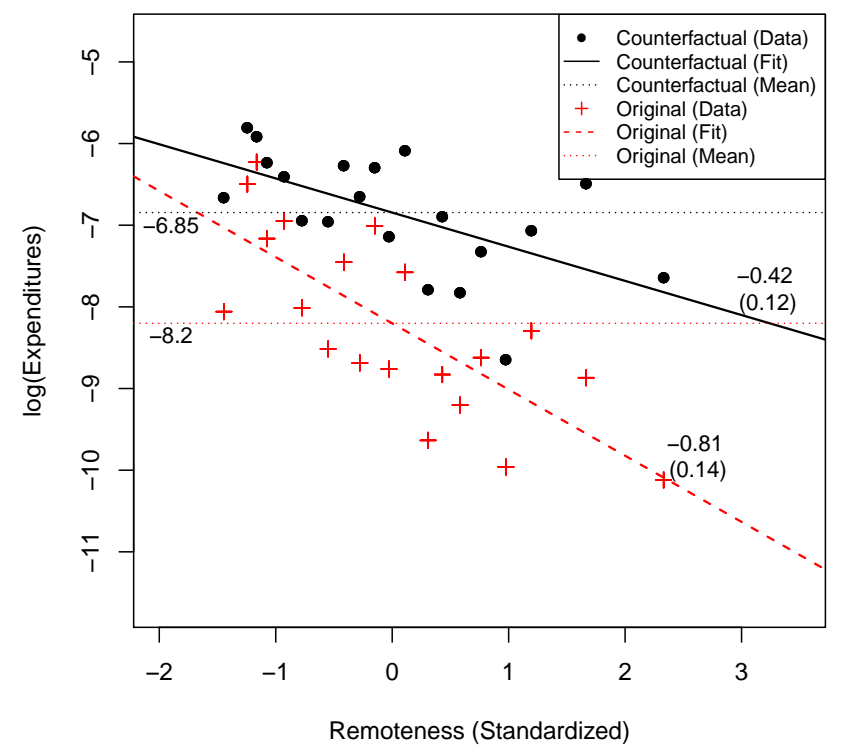

Adoption

50\% Reduction in Distributor-Agrovet Transport

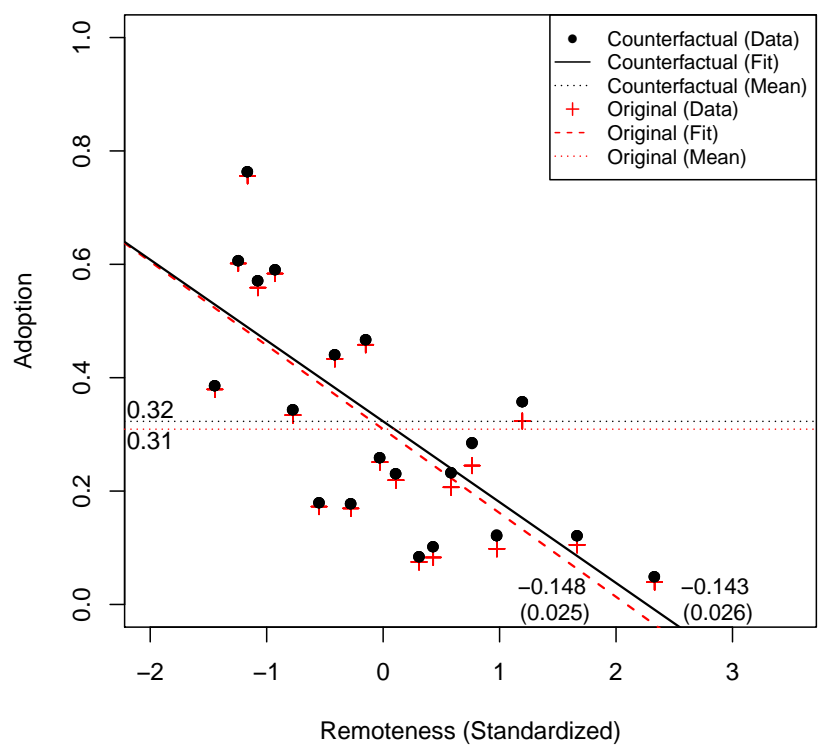

Fertilizer Expenditures $50 \%$ Reduction in Distributor-Agrovet Transport

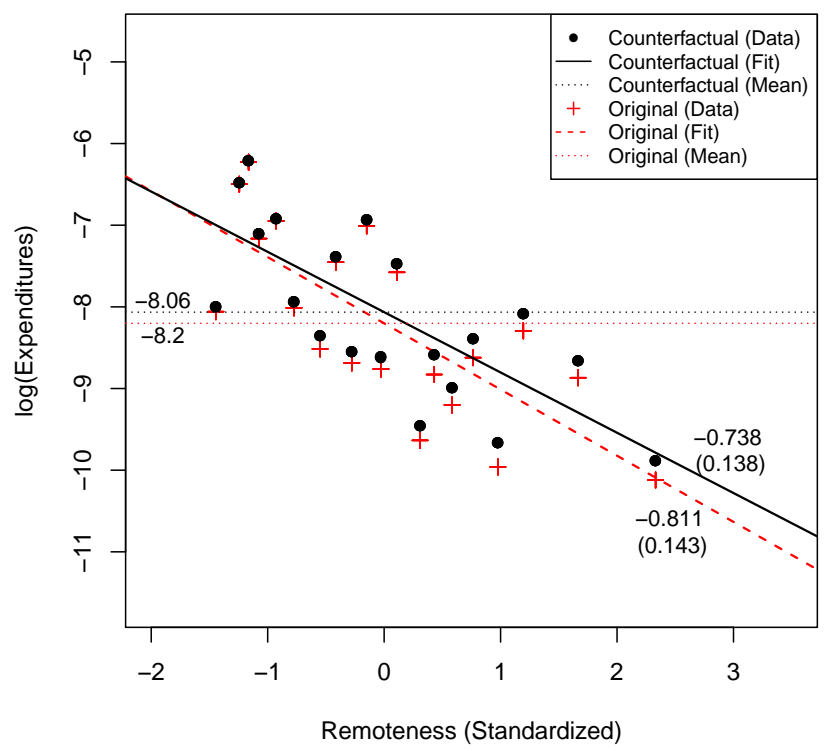

Notes: See text for discussion of counterfactuals. 
$\%$ Change in Aggregate Adoption and Additional Entry

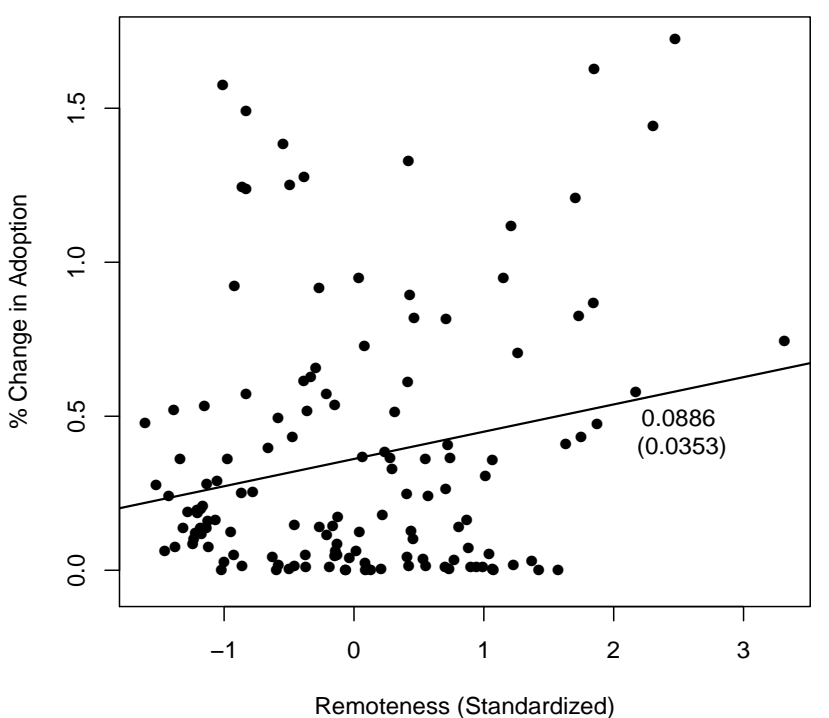

Adoption

50\% Reduction in Pecuniary Trade Cost to all Maize Markets

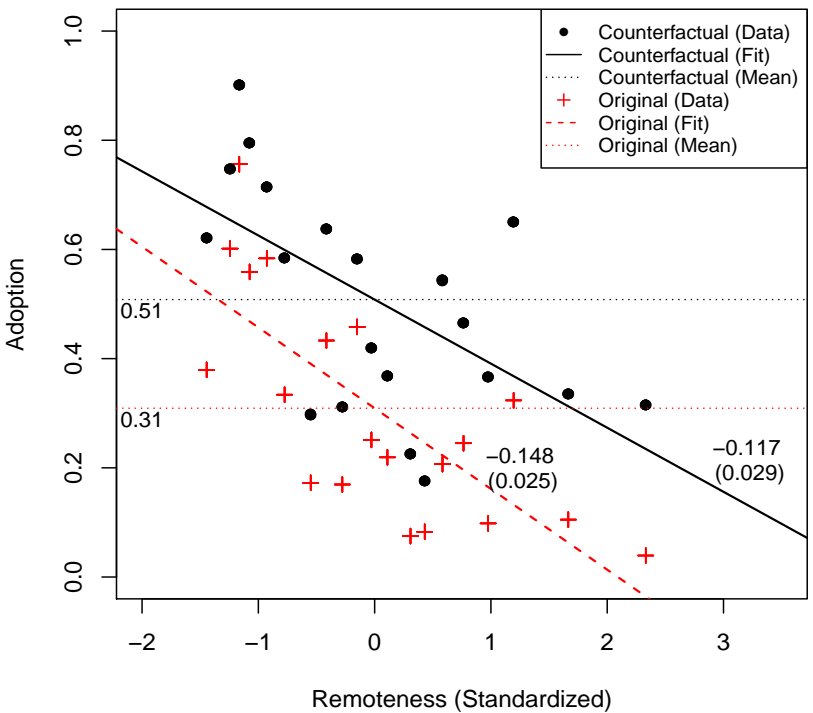

$\log$ (Entrant Profits) and Additional Entry

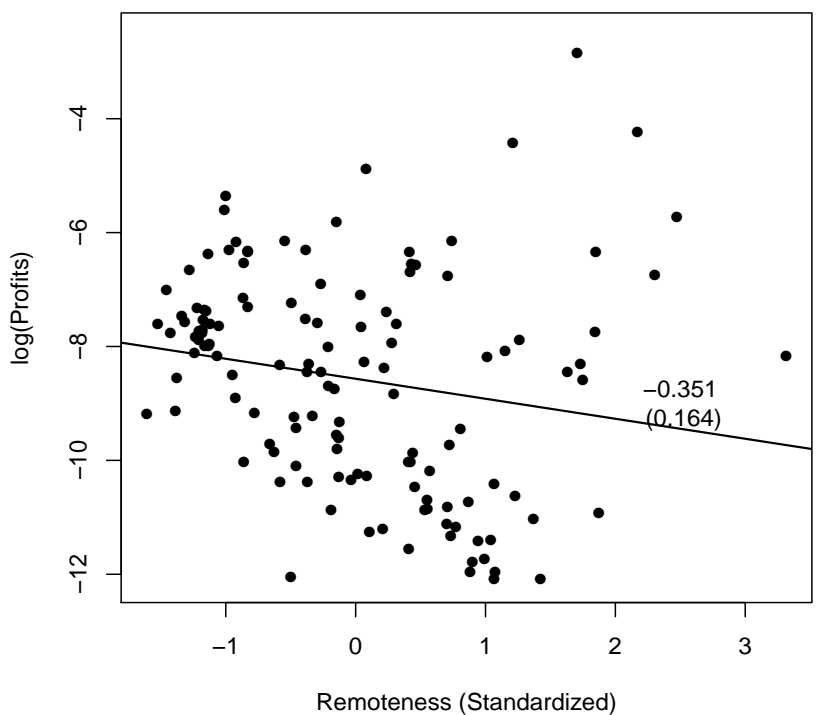

Adoption $\mathbf{5 0 \%}$ Reduction in Iceberg to Nearest Market

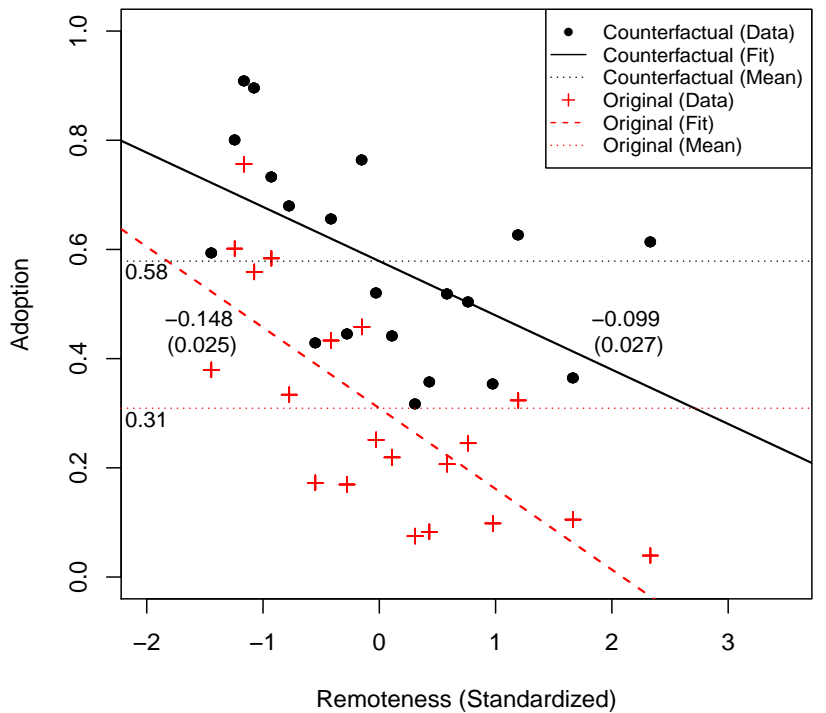

Notes: See text for discussion of counterfactuals. 
Web Appendix Table A1. Survey Compliance Rates

\begin{tabular}{lccc}
\hline \hline & $(1)$ & $(2)$ & $(3)$ \\
Farmer surveys 2016 & Survey Attempts & Completed & Compliance Rate \\
\cline { 2 - 4 } Farmer surveys 2017 & 583 & 573 & 0.98 \\
Agrovet surveys & 2535 & 2477 & 0.98 \\
Maize sellers at markets & 585 & 532 & 0.91 \\
\hline
\end{tabular}

Notes: see text of details of surveys. 
Web Appendix Table A2. Costs of transporting fertilizer and transporting farmer, by distance

Cost of transporting fertilizer from agrovet in destination village

Cost of farmer traveling (standardized to $50 \mathrm{~kg}$ )

Google maps: kilometers to destination

\begin{tabular}{cccc}
\hline $0.036 * * *$ & \multicolumn{3}{c}{$0.047 * * *$} \\
$(0.020)$ & & $(0.007)$ & \\
& $1.276^{* * *}$ & & $1.831 * * *$ \\
& $(0.677)$ & & $(0.260)$ \\
73 & 73 & 119 & 119 \\
341 & 341 & 988 & 988 \\
\hline
\end{tabular}

Google maps: hours to destination

Number of villages himself to agrovet

Number of observations

Notes: Data is constructed from Farmer Surveys, conditional on making input purchases and/or selling output. Clustered standard errors (by village) are reported in parentheses.

$*, * *$, and $* * *$ indicate significance at $10 \%, 5 \%$, and $1 \%$ respectively. 
(1)

(2)

Coefficient from regression

Mean on standardized distance from regional hubs

Panel A. Agrovet shop-level ( $\mathrm{N}=507)$

Sells fertilizer

0.87

$-0.03$

$(0.34)$

$(0.02)$

Number of varieties of fertilizer

Quantity of fertilizer sold last year $(\mathrm{kg})$

1.76

$-0.15^{*}$

(1.58)

(0.09)

5995

$-473.41$

Sells seeds

(12721)

$(757.30)$

0.72

0.04

$(0.45)$

(0.02)

Number of varieties of seeds

1.2

0.10

(1.26)

(0.07)

Quantity of seeds sold last year $(\mathrm{kg})$

2194

(8008)

0.64

(0.69)

$(557.99)$

$0.30 * * *$

$(0.04)$

Panel B. Prices and markups (Agrovet shop-variety level, N=938)

Retail price for 50 kilograms

$0.65^{* * *}$

Wholesale price for 50 kilograms

$(0.22)$

21.43

$0.16^{*}$

(4.14)

$(0.09)$

Markup (percentage points) ${ }^{1}$

Notes: In Column 1, standard deviations are in parentheses. In Column 2, standard errors in parentheses. Regressions in Panel B includes type and brand fixed effects.

$*, * *$, and $* * *$ indicate significance at $10 \%, 5 \%$, and $1 \%$.

${ }^{1}$ Markup accounts for cost of transport to wholesaler. 
(1)

Mean

Panel A. Robustness to Dropping Villages Within 10km of Regional Borders

A1. Input Side: Travel-cost adjusted fertilizer prices faced by farmers

Minimum travel-cost adjusted price for $50 \mathrm{~kg}$ of Urea1

Decomposition of price between retail price and cost of transportation

Retail price at the location with the lowest travel-cost adjusted price (USD)

Cost of travel to obtain minimum travel-cost adjusted price (USD)

A2. Output Side: Travel-cost adjusted maize prices if farmers were to sell in a local market

Market survey: maximum travel-cost adjusted price

30.07

immediately after 2017 harvest (USD)

Decomposition of price between retail price and cost of transportation

Retail price at the location with the highest travel-cost adjusted price (USD)

Cost of travel to obtain the highest travel-cost adjusted price (USD)

Coefficient from regression on standardized distance from regional hubs
$(4.44)$

19.91

(2.67)

4.069
$2.70 * * *$

$1.32 * * *$

$1.38 * * *$
$-3.71 * * *$

$0.89 * * *$

$4.60 * * *$

$(0.21)$
Panel B. Bounding regression coefficients by assigning prices to missing retailers ${ }^{1}$ Input Side: Travel-cost adjusted fertilizer prices faced by farmers

Minimum travel-cost adjusted price for $50 \mathrm{~kg}$ of Urea $^{1}$

Decomposition of price between retail price and cost of transportation

Retail price at the location with the lowest travel-cost adjusted price (USD)

$1.10 * * *$

Cost of travel to obtain minimum travel-cost adjusted price (USD)

4.25

$1.16^{* * *}$

(4.35)

Notes: Data is from the universe of villages in Kilimanjaro and Manyara region $(\mathrm{N}=1183)$. The unit of observation is the village. Travel costs imputed from transport surveys and Google maps. In Column 1, standard deviations are in parentheses. In Column 2 , standard errors in parentheses.

$*, * *$, and $* * *$ indicate significance at $10 \%, 5 \%$, and $1 \%$.

${ }^{1}$ In this calculation, we imputed prices to retailers with missing values. To do this, we estimated the distribution of prices within region. We then assigned high or low prices to the missing agrovet (defined as being at the 10th or 90th percentile of this price distribution) in a way that attenuated the regression coefficient. For example, a missing agrovet in a remote village was assigned a low price, causing a flattening of the regression. 
Web Appendix Table A5. Input and output market price dispersion across countries

(1)

(2)

Secondary Datasets

Tanzania Data ${ }^{2}$

Residual standard deviation in log prices for: ${ }^{3}$

All products

Maize only

0.45

0.34

0.15

Fertilizer only

0.12

0.10

Notes: Secondary datasets include RATIN (prices of major crops across 41 major markets in 5 countries - Kenya, Tanzania, Uganda, Burundi, and Rwanda - over the 1997-2015 time period), Africafoodprices.io (25 products over 276 markets in 53 countries), AMITSA (the Regional Agricultural Input Market Information and Transparency System for East and Southern Africa, which includes information on 9 fertilizer varieties in 95 markets in 8 countries), prices of 5 major varieties of fertilizer (Urea, CAN, DAP, and NPK 1717 17) in 18 countries from 2010-16 in Africafertilizer.org; and prices of a number of commodities in 38 countries from 1992-2016 collected by the WFP.

${ }^{1}$ Maize prices are from a survey of market sellers in 98 markets conducted in October 2017. Fertilizer prices are from surveys of agro-input retailers in 2017.

${ }^{2}$ Calculated from a regression of log prices on product, country, and time fixed effects. See text for details. 
Panel A. Secondary Datasets

Log (distance)

Log (travel time)

$0.03 * * *$

Dependent variable: Absolute log price difference

Products
Dependent variable mean
Dependent variable sd
Observations
Number of locations
Countries

Panel B. Northern Tanzania

\section{Log (distance)}

Log (travel time)

$\begin{array}{cc}\text { All } & \text { All } \\ 0.21 & 0.21 \\ 0.20 & 0.20 \\ 4,752,196 & 4,752,196 \\ 1335 & 1335 \\ 49 & 49\end{array}$

$\begin{array}{cc}\text { All } & \text { Maize } \\ 0.21 & 0.20 \\ 0.20 & 0.17 \\ 4,752,196 & 675,880 \\ 1335 & 1335 \\ 49 & 43\end{array}$

$\begin{array}{ccc}0.01 * * * & & -0.030 \\ (0.003) & & (0.020) \\ & 0.01 * * * & 0.04 * \\ & (0.004) & (0.025)\end{array}$

\begin{tabular}{|c|c|c|}
\hline \multirow[t]{3}{*}{$\begin{array}{l}0.03 * * * \\
(0.011)\end{array}$} & & $\begin{array}{l}-0.10^{* * *} \\
(0.050)\end{array}$ \\
\hline & $0.04 * * *$ & $0.16^{* *}$ \\
\hline & $(0.016)$ & $(0.069)$ \\
\hline
\end{tabular}

\section{Products}

Dependent variable mean

Dependent variable sd

Observations

$\begin{array}{cccc}\text { All } & \text { All } & \text { All } & \text { Maize } \\ 0.16 & 0.16 & 0.16 & 0.21 \\ 0.14 & 0.14 & 0.14 & 0.18 \\ 22,386 & 22,376 & 22,376 & 6,873 \\ 82 & 82 & 82 & 65\end{array}$

$\begin{array}{cc}0.000 & 0.000 \\ 0.000 & (0.015) \\ 0.04 * * * & 0.04 * *\end{array}$

$0.01 * * *$

(0.002)

(0.003) (0.017)

$\begin{array}{cc}\text { Maize } & \text { Maize } \\ 0.20 & 0.20 \\ 0.17 & 0.17 \\ 675,880 & 675,880 \\ 1335 & 1335 \\ 43 & 43\end{array}$

(0.016)

$\begin{array}{cc}\text { Maize } & \text { Maize } \\ 0.21 & 0.21 \\ 0.18 & 0.18 \\ 6,873 & 6,873\end{array}$

$\begin{array}{cc}0.000 & 0.010 \\ 0.000 & (0.014) \\ 0.01 * * * & 0.000 \\ (0.002) & (0.016)\end{array}$

Fertilizer Fertilizer Fertilizer

$\begin{array}{lll}0.11 & 0.11 & 0.11\end{array}$

$\begin{array}{lll}0.13 & 0.13 & 0.13\end{array}$

$38,364 \quad 38,364 \quad 38,364$

$1335 \quad 1335 \quad 1335$

$\begin{array}{lll}18 & 18 & 18\end{array}$

$65 \quad 65$

$\begin{array}{ccc}0.003^{*} & & 0.007 \\ (0.002) & & (0.017) \\ & 0.004 & -0.004 \\ & (0.002) & (0.019) \\ & & \\ \text { Fertilizer } & \text { Fertilizer } & \text { Fertilizer } \\ 0.13 & 0.13 & 0.13 \\ 0.10 & 0.10 & 0.10 \\ 15,064 & 15,056 & 15,056 \\ 60 & 60 & 60\end{array}$

Notes: Regressions include product, month and year fixed effects. All regressions are within country. Travel time and distances calculated from Google maps. See Web Appendix Table A3 and text for discussion of datasets.

Two-way clustered standard errors in parentheses. $* * * * *$, and * indicate significance at $1 \%, 5 \%$, and $10 \%$. 
Web Appendix Table A7. Adoption in LSMS-ISA surveys

Dependent variable: used chemical fertilizer in last season

Log of distance to nearest major market $(\mathrm{km})$ $-0.027 * * *$ $(0.005)$

Log of distance to nearest population center $(\mathrm{km})$ $-0.019 *$

Dependent variable mean

0.32

0.32

Independent variable mean

3.21

Independent variable sd

1.27

Observations

35,938

1.02

Individuals

26,653

35,938

Notes: Regressions include World Bank LSMS-ISA household panel surveys in Ethiopia, Niger, Nigeria, Malawi, Tanzania, and Uganda. Standard errors clustered at the enumeration area level are in parentheses.

$* * *, * *$, and $*$ indicate significance at $1 \%, 5 \%$, and $10 \%$. 


\begin{tabular}{|c|c|c|c|}
\hline \multirow[b]{3}{*}{$\log ($ Labor/Acres $)$} & \multicolumn{2}{|l|}{ (1) } & \multirow[t]{2}{*}{ (2) } \\
\hline & \multicolumn{2}{|c|}{ Dependent variable: $\log ($ Harvest/Acres $)$} & \\
\hline & $\begin{array}{c}0.419 * * * \\
(0.042)\end{array}$ & $\begin{array}{c}0.433 * * * \\
(0.042)\end{array}$ & $\begin{array}{c}0.430 * * * \\
(0.042)\end{array}$ \\
\hline \multirow[t]{2}{*}{$\log ($ Labor/Acres) x Used Fertilizer? } & $0.124^{*}$ & $0.124^{*}$ & $0.149 *$ \\
\hline & $(0.075)$ & $(0.074)$ & (0.077) \\
\hline \multirow{2}{*}{ Used Fertilizer? } & $(0.33)$ & $(0.33)$ & \\
\hline & $(0.300)$ & $(0.298)$ & \\
\hline District-Year fixed effects & & $\mathrm{X}$ & \\
\hline District-Year-Fertilizer Use fixed effects & & & $\mathrm{X}$ \\
\hline Plot fixed effects & $\mathrm{X}$ & $\mathrm{X}$ & $\mathrm{X}$ \\
\hline Observations & 3,395 & 3,395 & 3,395 \\
\hline Plots & 2,554 & 2,554 & 2,554 \\
\hline
\end{tabular}




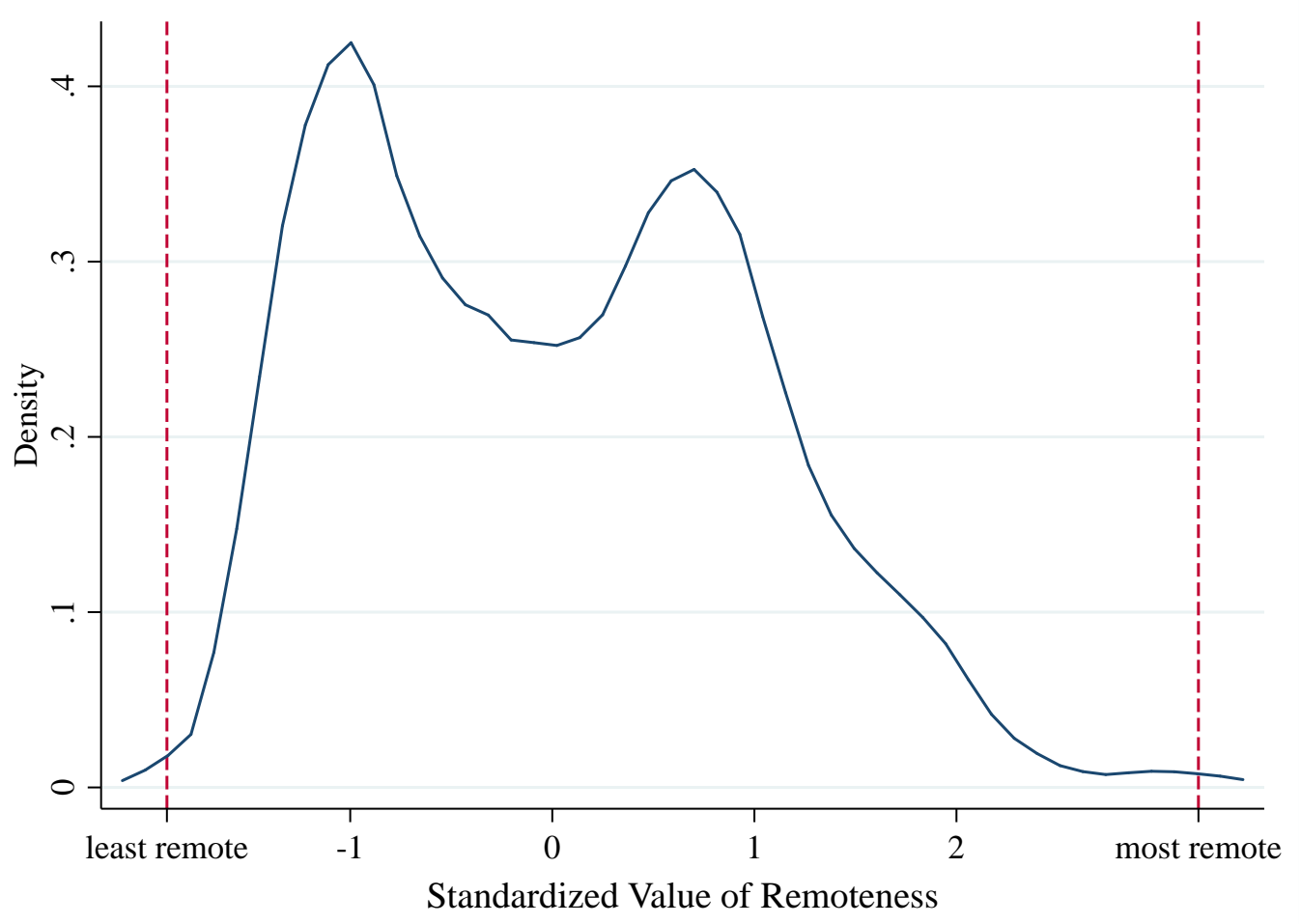

Notes: Remoteness at the village level. Vertical dotted lines indicate the villages with minimum and maximum remoteness. 


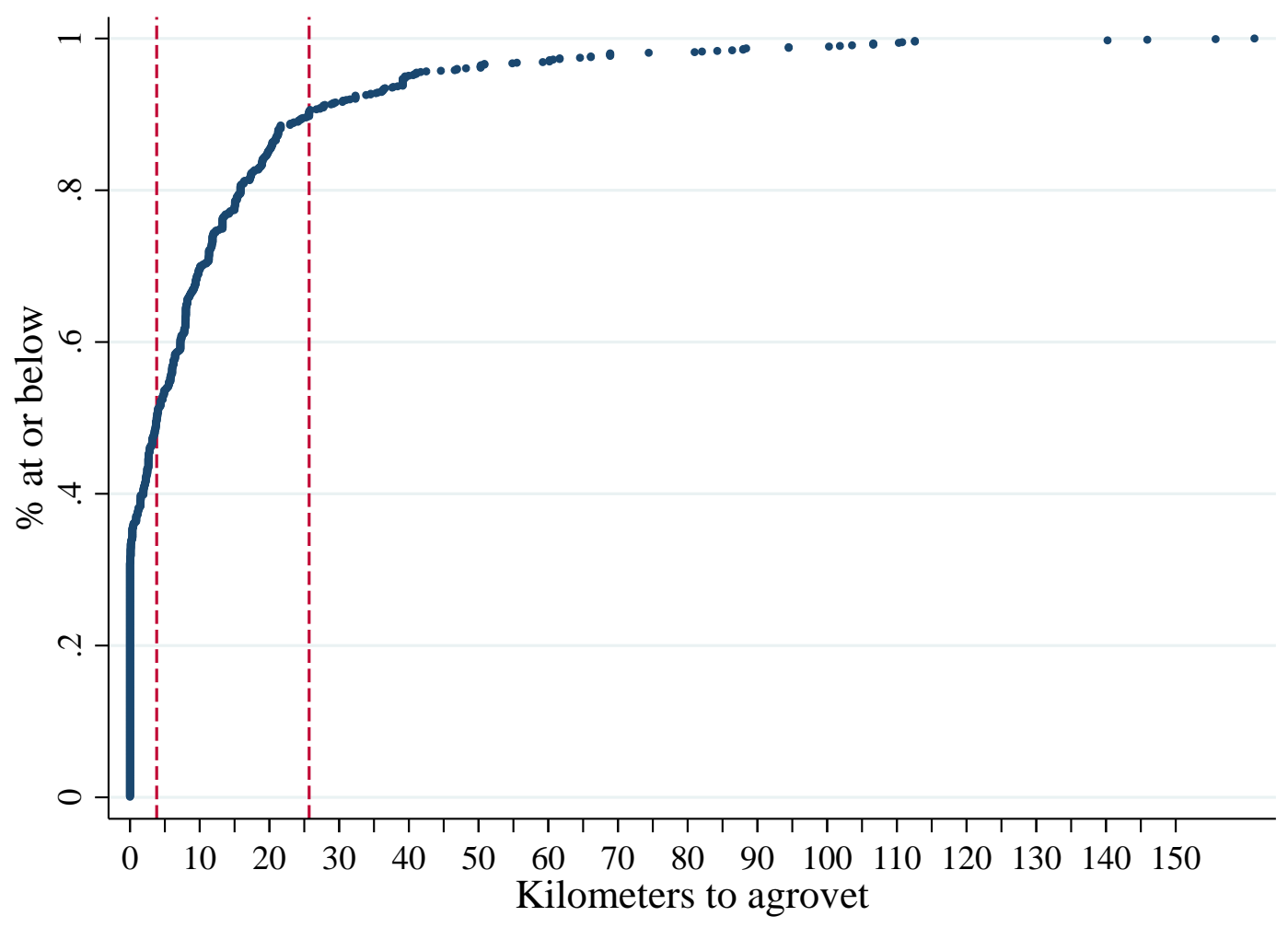

Notes: Each point represents a farmer. Purchase events include any kinds of agricultural inputs. Vertical dotted lines indicate distances corresponding to the the 50th and 90th percentile. 